\title{
Development of a Technique for In Situ Measurement of Water at the Asphalt/Model Siliceous Aggregate Interface
}

Tinh Nguyen

W. Eric Byrd

Dale Bentz

James Seiler, Jr.

Building and Fire Research Laboratory

Gaithersburg, Maryland 20899

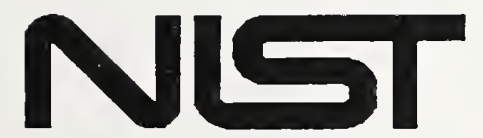

United States Department of Commerce

Technology Administration

National Institute of Standards and Technology 


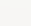




\section{Development of a Technique for In Situ Measurement of Water at the Asphalt/Model Siliceous Aggregate Interface}

Tinh Nguyen

W. Eric Byrd

Dale Bentz

James Seiler, Jr.

March 1992

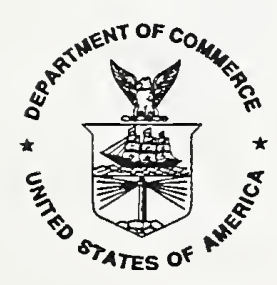

U.S. Department of Commerce Barbara Hackman Franklin, Secretary Technology Administration

Robert M. White, Under Secretary for Technology National Institute of Standards and Technology John W. Lyons, Director
Prepared for

Strategic Highway Research Program

National Research Council

Washington, DC 20006 



\section{Table of Contents}

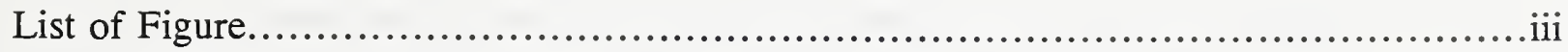

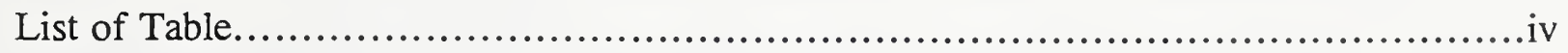

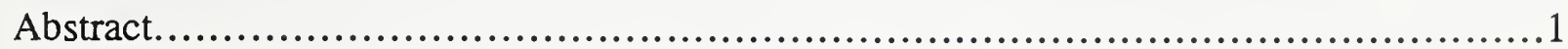

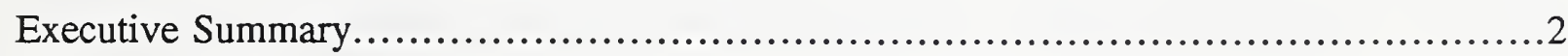

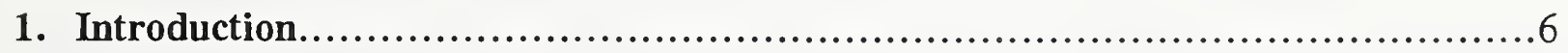

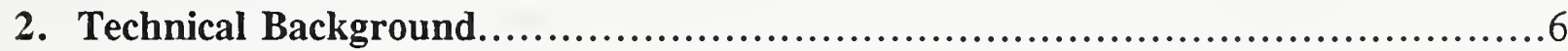

2.1. Nature of Asphalt/Siliceous Aggregate Bonds in Water ...........................6

2.2. Multiple Internal Reflection Spectroscopy.......................................7

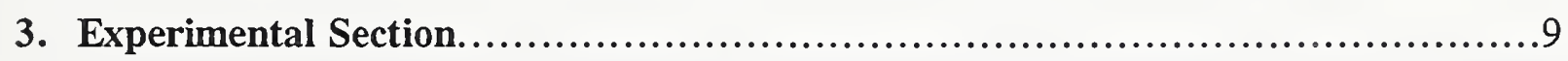

3.1. Materials..........................................................................9

3.2. Specimen Preparation.............................................................11

3.3. Measurement of Water at the Asphalt/Model Siliceous Aggregate Interface........................................................................12

3.4. Establishment of a Concentration-Intensity Calibration Curve for Water...........13

3.5. Water Absorption Measurement of SHRP Asphalts...............................13

4. Results................................................................................ 13

4.1. FTIR-MIR Analysis of SHRP Asphalts before Water Exposure ..................13

4.2. FTIR-MIR Analysis of Asphalt/Model Siliceous Aggregate in Water..............15

4.3. Water Intensity-Concentration Calibration Curve................................16

4.4. Depth of FTIR-MIR Probing at the Asphalt/Siliceous Aggregate Interface .......17

4.5. Water Absorption Characteristics of SHRP Asphalts............................17

4.6. Quantitative Measurements of Water at the Asphalt/Model Siliceous Aggregate Interface.....................................................................19

4.7. Apparent Diffusion Coefficients of Water through SHRP Asphalts on Aggregate.21

4.8. Bond Strength of Asphalt on an Aggregate in Water................................24

5. Impact on Highway Technology ..............................................24

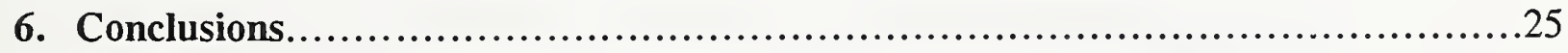

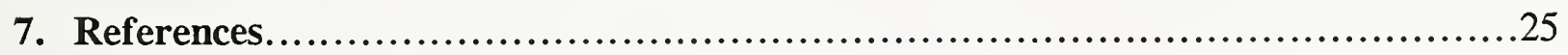




\section{List of Figures}

Figure 1. Optical diagram of a multiple internal reflection spectroscopy experiment showing the amplitude decay of the evanescent wave.

Figure 2. Specimen configuration and experimental setup for in situ measurement of water at the asphalt/model siliceous aggregate interface.

Figure 3. a) FTIR-MIR spectra of the five SHRP asphalts-on a siliceous aggregate before exposure to water, and b) expanded spectra in the $1200-1800 \mathrm{~cm}^{-1}$ region.

Figure 4. Examples of unprocessed FTIR-MIR spectra of an asphalt/model siliceous aggregate system exposed to water for SHRP asphalts; a: AAK-1 and b: AAM-1.

Figure 5. FTIR-MIR difference spectra (water exposed - unexposed) for the five SHRP asphalts on a model siliceous aggregate; a: AAC-1, b: AAD-1, c: AAG-1, d: $\mathrm{AAK}-1$, and $\mathrm{e:} \mathrm{AAM-1.}$

Figure 6. FTIR-MIR spectra of liquid water in contact with a siliceous aggregate.

Figure 7. Intensity increase of water $\mathrm{OH}$ group as a function of exposure time for the five SHRP asphalts on a model siliceous aggregate. (Each dot represents one data point.)

Figure 8. Intensity decrease of asphalt $\mathrm{CH}$ group as a function of exposure time for the five SHRP asphalts on a model siliceous aggregate. (Each dot represents one data point.)

Figure 9. FTIR-MIR spectra of water at various concentrations in $\mathrm{D}_{2} \mathrm{O}$ solutions in contact with a siliceous aggregate.

Figure 10. FTIR-MIR intensity-concentration calibration curve for water in contact with a siliceous aggregate.

Figure 11. Penetration depth of the evanescent wave in asphalt and in water as a function of wavelength.

Figure 12. Water absorption in five SHRP asphalts as a function of time. (The vertical bar at each data point indicates the deviation from the mean.)

Figure 13. Surface appearances of five SHRP asphalts before and after exposure to water for 1075 hours. 
Figure 14. Light microscopy photographs of AAD-1 and AAK-1 asphalts after exposure to water for 1075 hours, showing: (a) fine-textured structure on the surface of AAK-1, (b) coarse-textured structure on surface (light orange area) and unchanged asphalt material underneath (black area) of AAD-1, and (c) craters on surface of AAD-1.

Figure 15. Light microscopy photographs of AAC-1, AAG-1, and AAM-1 asphalts after exposure to water for 1075 hours, showing orange skin-like surfaces of all three asphalts (6.25x magnification), and presence of large pinholes on AAC-1 (6.25x) and smaller pinholes AAM-1 (25x).

Figure 16. Thickness of the water layer at the asphalt/model siliceous aggregate interface for five SHRP asphalts.

Figure 17. Total water detected near the asphalt/model siliceous aggregate interface (upper curves) and amount of the water layer at the asphalt/model siliceous aggregate interface (lower curves) for five SHRP asphalts.

Figure 18. Effect of water exposure on the bond strength of asphalt on a soda glass surface.

\section{List of Table}

Table 1. Some properties of five SHRP straight asphalts selected for the study (from Ref. 39)

Table 2. Thickness of the water layer and mass of water at the asphalt/model aggregate interface for five SHRP asphalts at three exposure times

Table 3. Apparent diffusion coefficients of water through SHRP asphalts and some polymeric films 
- 


\begin{abstract}
A technique based on Fourier transform infrared (FTIR) spectroscopy in the multiple internal reflection (MIR) mode was developed for measuring water in situ at the interface between an asphalt and a model siliceous aggregate. The technique required the coating of an asphalt layer of known thickness on an internal reflection element (IRE), which served as an optical guide to obtain an infrared spectrum. A water chamber was attached to the asphalt-coated IRE, and FTIR-MIR spectra were taken automatically at specified times without disturbance of the specimens. In situ water measurements for five Strategic Highway Research Program (SHRP) core asphalts (AAC-1, AAD-1,AAG-1, AAK-1, and AAM-1) on a hydrated, $\mathrm{SiO}_{2}$-covered Si IRE, which served as the model siliceous aggregate, were carried out using the technique. An FTIRMIR study of water at different concentrations and experiments on water absorption in SHRP asphalts were also done for the quantitative analysis. Calculations were made to demonstrate that the water detected was at or near the asphalt/siliceous aggregate interface. The results have shown that the technique can detect and quantify water in situ at the asphalt/siliceous interface, and provide unique information on the transport properties of water through an asphalt layer attached to a substrate. The technique developed here should be useful for evaluating asphalt/siliceous model aggregate mixtures in terms of 1) water susceptibility of an asphalt/aggregate mixture, 2) effectiveness of antistripping agents, 3) effects of aggregate surface contamination and environmental temperature on water stripping, and 4) water diffusion through asphalts on an aggregate. The technique should also be effective in obtaining quantitative information on the transport of water and other compounds, both organic and inorganic, through a layer of any thickness of asphalt/aggregate mixture, cement, and concrete attached to a substrate. Results of an exploratory test method for measuring the bond strength of an asphalt on an aggregate in the presence of water are given.
\end{abstract}

Keywords:Aggregate, asphalt, asphalt/aggregate interface, ATR spectroscopy, bonding strength, diffusion, FTIR, in situ measurement, model aggregate, multiple internal reflection spectroscopy, SHRP, quantitative, siliceous aggregate, stripping, water, water absorption, water susceptibility. 


\section{Executive Summary}

\section{Introduction}

The debonding of asphalt from mineral aggregates in the presence of water (stripping) has been a problem ever since asphalt paving came into existence. Many studies have sought a solution to the problem, but stripping continues to occur. In recent years, there seem to have been more frequent premature failures of pavements due to stripping. When asphaltic concretes fail, they require large replacement costs; the costs could be reduced if there were effective methods for evaluating stripping resistance of asphalt/aggregate mixtures. A Strategic Highway Research Program (SHRP) contract (ID-27) was charged with developing a nondestructive technique for measuring the stripping of asphalt from a siliceous aggregate in the presence of water. The main objective of the first phase of this study was to develop a spectroscopic technique for measuring in situ water at the interface between an asphalt and a model siliceous aggregate. This report describes the successful development of the water in situ measurement technique. The work was carried out at the National Institute of Standards and Technology (NIST).

\section{Experiments}

Measuring and quantifying water in situ at the asphalt/model aggregate interface was based on Fourier transform infrared (FTIR) spectroscopy in the multiple internal reflection (MIR) mode. The developed technique used a hydrated, $\mathrm{SiO}_{2}$-covered $\mathrm{Si}$ internal reflection element (IRE) as the model siliceous aggregate. The IRE served as an optical guide to obtain the infrared spectrum. Five SHRP asphalts, AAC-1, AAD-1, AAG-1, AAK-1, and AAM-1, were used for the study. Asphalts were heated to $60^{\circ} \mathrm{C}$ and applied on the model aggregate using a "drawdown" technique. The thickness of the asphalt films on the model aggregate was $63 \pm 15 \mu \mathrm{m}$. A water chamber was attached to the asphalt-coated model aggregate and water was introduced into the chamber. At specified time intervals, FTIR-MIR spectra were taken automatically without realignment of the instrument accessory and without disturbance of the specimens. Difference spectra between the water-exposed and unexposed asphalt-coated aggregate specimens as a function of exposure times were collected to accentuate the effect of water. To translate FTIR information to the amount and thickness of the water layer at the asphalt/aggregate interface, FTIRMIR analyses were made of water at different concentrations in $\mathrm{D}_{2} \mathrm{O}$ and experiments on water absorption in the asphalts were carried out. The water absorption experiment was performed using the gravimetric method and $63-\mu \mathrm{m}$ asphalt films on thin aluminum plates. The coated specimens were immersed in distilled water, taken out, blotted, and weighed at desired intervals up to 310 hours; the amount gained was expressed in percent by mass of the original asphalt. FTIR-MIR analyses of different water concentrations were done using a water chamber attached to an asphalt-free model aggregate and filling the chamber with each $\mathrm{H}_{2} \mathrm{O} / \mathrm{D}_{2} \mathrm{O}$ solution. The feasibility of developing a test method to measure the bond strength of an asphalt to an aggregate in the presence of water was also investigated using a portable, pneumatic adhesion tester and a special probe which provides pathways for water transport through the asphalt to the asphalt/aggregate interface.

\section{Results}

\section{FTIR-MIR Analysis of Asphalt/ Model Siliceous Aggregate Exposed to Water}

FTIR-MIR spectra after water exposure showed that the intensities of the water bands increased while 
those of the asphalt bands decreased, as a function of time of exposure. The increases and decreases were rapid initially, then slowed down. The water bands were verified by the spectrum of the liquid water in contact with the asphalt-free model aggregate. The effects of water on the asphalt-coated model aggregate were different for the five SHRP asphalts. The intensities of the water bands of the AAD-1 asphalt increased substantially over the first 45 hours then levelled off, while those of the other asphalts increased more slowly (than AAD-1) but continued to increase even after much longer times. These results indicated that the technique is effective for detecting in situ water taken up by an asphalt-coated siliceous aggregate system.

\section{FTIR-MIR Probing Depth at the Asphalt/Model Aggregate Interface}

To define the range of depths within the asphalt/model aggregate system in which the water molecules could be detected, a calculation of the FTIR-MIR probing depth in the asphalt and water materials as a function of the infrared wavelength was performed. The results showed that water detected was within a depth of $<0.25 \mu \mathrm{m}$ from the sample/aggregate interface, indicating that the technique detects water molecules at or very near the asphalt/aggregate interface. There is a small difference in the probing depth depending on whether water or asphalt is at the asphalt/model aggregate interface, $0.243 \mu \mathrm{m}$ for asphalt versus $0.225 \mu \mathrm{m}$ for water at $2.94 \mu \mathrm{m}$ wavelength.

\section{Water Absorption Characteristics of SHRP Asphalts}

To account for water uptake in the asphalt near the asphalt/aggregate interface apart from the total water detected, water absorption data for five SHRP asphalts were collected. AAD-1 and AAK-1 picked up the most water, approximately $6.0 \%$ by mass after 300 hours, while AAM-1 picked up the least, $1.2 \%$ after the same exposure period. The color of the AAD-1 and AAK-1 specimen surfaces changed markedly, from black to grey after 50 hours of exposure, while those of AAM-1 and AAC-1 did not change even after more than 1000 hours. AAG-1 specimens turned from black to dark brown. Light microscopy studies of the samples after 1000-hour exposure revealed that the surfaces of AAD- 1 and AAK-1 asphalts had a highly-textured structure. Further, AAD-1 surface had a coarser texture, which contained numerous holes and craters. The surfaces of AAC-1, AAG-1, and AAM-1 became wavy and resembled an orange-skin appearance after water exposure. Surfaces of AAC-1 and AAM-1 contained many pinholes after exposure. This is in contrast to all of the unexposed asphalts, whose surfaces appeared smooth and featureless.

\section{Water Concentration-Intensity Calibration Curve}

To translate FTIR-MIR spectral information to the amount and thickness of water at the asphalt/aggregate interface, a FTIR-MIR concentration-intensity calibration curve for water was established using eight different concentrations of water in solution in $\mathrm{D}_{2} \mathrm{O}$. FTIR-MIR spectra of the eight solutions showed that the water $\mathrm{OH}$ stretching bands at the higher water concentrations were asymmetrical. The $\mathrm{OH}$ bending mode of water was only visible at water concentrations $>20 \%$, indicating this band has a much lower IR absorption than the stretching band. For this reason, the peak height of the OH stretching band was chosen for the quantitative analysis. The concentration-intensity plot for water did not follow a linear relation, but deviated from linearity at high concentrations. 


\section{Quantitative Measurements of Water at the Asphalt/Aggregate Interface}

The water detected near the asphalt/aggregate interface was the sum of water absorbed in the asphalt within the FTIR-MIR probing depth and of the water at the asphalt/aggregate interface. This was expressed mathematically, which allowed the calculation of the amount and thickness of the water layer at the asphalt/model aggregate interface. The water absorbed in the asphalt within the probing depth was determined and subtracted from the total amount. The latter was derived from the intensity-exposure time and the concentration-intensity calibration curves. The results showed that the thickness of the water layer at the asphalt/model aggregate interface varied with exposure times and with the asphalt types. For example, after 50 hours immersion, AAD-1 had a 85 nm-thick water layer, while AAC-1, AAG-1, AAK1 , and AAM-1 had thicknesses ranging from 20 to $28 \mathrm{~nm}$ after the same period. The thickness of the water layer of AAD-1 did not change after 50 hours, but that of the other asphalts continued to increase for some time. The technique should be equally applicable to providing quantitative information on organic or inorganic compounds at the asphalt/siliceous aggregate interface.

\section{Diffusion Coefficient of Liquid Water through SHRP Asphalts on Aggregate}

The developed technique measured the water at the asphalt/aggregate interface after the water had migrated through the asphalt: This technique is, therefore, suitable for measuring the apparent diffusion coefficient of water through asphalt films. Indeed, the technique is unique for studying the diffusion processes of water in asphalts, asphalt/aggregate mixtures, or polymeric films adhered to a substrate. No such method was previously available. Apparent diffusion coefficients were determined for AAD-1, AAG-1, and AAK-1 asphalts which showed an average value of $2.4 \times 10^{-10} \mathrm{~cm}^{2} \mathrm{~s}^{-1}$. The values varied by a factor of about two for these three asphalts. The developed technique should be applicable to obtaining information on water transport through a layer of asphalt/aggregate mixture, concrete, or any material on a substrate.

\section{Bond Strength of Asphalt on Aggregate in Water}

To utilize this non-destructive method for studying the stripping problem of asphalt, the information obtained must be related to the results of a bond strength test of asphalt on the aggregate in water. No such test is available at present. In preparing for the second phase work, we explored the development of such a test. The preliminary results are encouraging. The bond test combined the use of the portable, pneumatic adhesion tester developed at NIST for testing the adhesion of paint on a substrate and of a special probe developed during the exploratory work. The special probe provides pathways for water transport through the asphalt to the asphalt/aggregate interface, which weakens the bonds between the asphalt and the aggregate as a function of exposure. Preliminary results, for $150-\mu \mathrm{m}$ thick asphalt films on a soda glass, showed that, both before exposure and after short exposure times, the bond strength was determined by the cohesive strength of the asphalt. When water started to accumulate at the interface, the failure was at the asphalt/aggregate interface. This result is significant in that debonding of an asphalt from an aggregate due to ingress of water to the asphalt/aggregate interface was actually observed.

\section{Conclusions and Impact on Highway Technology}

A sensitive technique for measuring and quantifying water in situ at the asphalt/model siliceous aggregate interface has been developed. The technique is also unique for providing information on the transport of water through an asphalt layer of any thickness on a substrate. Information on the interfacial water 
layer and water transport through an asphaltic layer is essential for predicting the performance of asphalt and asphalt/aggregate mixtures in service. It is likely that the technique will have a wide range of applications in highway technology with regard to predicting water susceptibility of asphaltic concretes, studying the effects of the aggregate, contaminants on the aggregate, antistripping agents, and the asphalt itself, on the water susceptibility of asphalt/siliceous aggregate mixtures. The developed technique should also be useful for obtaining transport properties of water in asphalt/aggregate mixtures or concrete on a substrate. Further, the technique should be applicable to providing similar transport properties of organic and inorganic materials through a layer of an asphalt or any material on a substrate. 


\section{INTRODUCTION}

The debonding of asphalt from mineral aggregates in the presence of water (stripping) "has been observed at times ever since asphalt paving came into existence" (1). Since stripping was first recognized as a problem, many studies and hundreds of technical papers and articles have been devoted to the search for a solution to this problem. Several reviews on the subject have been written (2-5). Still, stripping continues to occur in many areas. In recent years, there seem to have been more frequent premature failures of pavements due to stripping of asphalt (6). As a result, antistripping agents have been used by many agencies to improve the water resistance of asphalt/aggregate mixtures (7). Whether asphalts fail prematurely or in the range of their expected service lifes, they require large replacement costs that could probably be reduced through development of effective methods for measuring the effects of water on the stripping of asphalt from an aggregate, for effectively evaluating the water resistance of an asphalt/aggregate mixture, and for evaluating the effectiveness of antistripping agents. A major technical barrier to overcoming the problem of stripping is the lack of a technique for measuring water at the asphalt/aggregate interface. If such a technique were available, it would make possible direct studies of the effects of water on the asphalt/aggregate interaction and, ultimately, predicting the stripping characteristics of an asphalt/aggregate pair in the presence of water.

Measuring water at bonded interfaces has been the subject of much interest, not only in the asphalt pavement area, but also many areas involving a polymer film on a substrate, such as coatings on substrates, adhesive bondings, and fiber composites $(8,9)$. A number of in situ methods have been developed for studies of chemical reactions at the aqueous electrolyte/electrode interface (10-12). However, until recent research at the National Institute of Standards and Technology $(13,14)$ that led to a technique for measuring water in situ at the coating/metal interface, there has been no suitable technique available.

The main objective of this first phase study was to develop a technique for measurement of water in situ at the interface between asphalt and a model siliceous aggregate.

\section{TECHNICAL BACKGROUND}

\subsection{Nature of Asphalt/Siliceous Aggregate Bonds in Water}

Acidic aggregates, such as siliceous aggregate, are generally more susceptible to stripping than basic aggregates, such as carbonate rocks (5). The chemistry of the surface of siliceous aggregates is similar to other polar solids, e.g. metals (oxides), in that the outermost layer is mostly hydroxylated $(8,15,16)$. Research on polymers on steel substrates (17) and related research on adhesives, including polymers on silica $(18,19)$, has demonstrated that the thermodynamic work of adhesion between polymers and metal substrates in the presence of water is highly negative. This indicates that the polymer/metal (oxide) bonds, which derive mostly from polar and dispersion force contributions, are unstable in the presence of water, and are readily broken by water. These observations are consistent with experience (18). Although many adhesion theories, such as mechanical adhesion (20), chemical adhesion (20,21), and 
molecular adhesion (22) have been proposed, the interfacial energy theory, which is based upon secondary force (polar and dispersion forces) interactions, is thought to best explain the adhesion of asphalt to aggregate $(5,21)$. This assertion that the asphalt/aggregate bonds are determined by the secondary force interactions is substantiated by recent intensive studies on the interactions between asphalts and aggregates (23). Consequently, the affinity for water on hydroxyl groups on a siliceous aggregate surface is expected to be greater than the secondary force interactions (including hydrogen, acid-base, and electrostatic interactions) between asphalts and aggregates. Thus, water will displace the asphalt from a siliceous aggregate. Indeed, the interfacial energy mechanism has been used to explain the stripping of asphalt from the aggregate surface by water $(21,24)$.

It has been recognized that silicate glass and metal oxide surfaces adsorb many layers of water at high relative humidities or in the presence of liquid water $(8,9,16)$. The presence of hygroscopic contaminants on the substrate surface also results in adsorption of multiple water layers at lower relative humidities. For example, at a relative humidity of $50 \%$, a surface contaminated with $10^{-7} \mathrm{gm} / \mathrm{cm}^{2}$ of potassium hydroxide would "adsorb" the equivalent of five molecular layers of water (25). The adsorbed layers closest to the oxide are strongly bonded and very difficult to remove. Therefore, the presence of a monolayer of water at the asphalt/aggregate interface would probably not interfere with the adhesion of an asphalt/aggregate mixture. However, increasing the coverage of water will, at some point, affect the strength of the asphalt/aggregate bonds. It has been demonstrated, for example, that interfacial water adsorption progressively decreases the bond strength between a metal (oxide) and an organic adhesive $(9,26-28)$.

In addition to attacking the asphalt/aggregate interface, water may also plasticize, hydrolyze, crack, and craze asphalts, accelerating the movement of water to the asphalt/aggregate interface. Water may enter the asphalt/aggregate interface in several ways: diffusion through the asphalt, transport along the interface at thin or defective areas, capillary action through cracks and pinholes, and migration from the interior of a saturated or partially saturated aggregate.

\subsection{Multiple Internal Reflection Spectroscopy}

The technique developed for measuring water at the asphalt/aggregate interface is based upon Fourier transform infrared - internal reflection (FTIR-IR) spectroscopy, commonly known as FTIR-ATR (attenuated total reflection) spectroscopy. The theory and principles of internal reflection spectroscopy are well understood (29). For surface and interface studies, multiple internal reflections (MIR) are normally used. FTIR-multiple internal reflection (FTIR-MIR) spectroscopy is an extremely sensitive method for studying molecular changes at the surface and interface. For example, it has been demonstrated that FTIR-MIR was able to detect one hundredth of a monolayer of stearic acid on a KRS-5 substrate (30). A brief background on the principle of the internal reflection spectroscopy is presented here to aid in understanding the results and discussion. 
A unique aspect of internal reflection spectroscopy is the use of an optically dense medium, internal reflection element, (IRE), as an optical guide to obtain an infrared spectrum. The infrared radiation incident above the critical angle is totally reflected at the IRE/air interface. At the point of reflection, the radiation goes out of the IRE and forms an evanescent wave, as observed by Newton (31) over 300 years ago. The evanescent wave is the interference wave of the incident and reflected waves. The amplitude of the evanescent wave decays exponentially with distance from the IRE surface, which is graphically depicted in Figure 1, following the equation (29)

$$
E=E_{o} * \exp \left(\frac{-z}{d_{p}}\right)
$$

where

$\mathrm{Z}$ is the depth in the sample from the IRE surface,

$\mathrm{E}$ and $\mathrm{E}_{\mathrm{o}}$ are the amplitudes of the electric field at depth $\mathrm{z}$ in the sample and at the IRE surface, respectively, and, $\mathrm{d}_{\mathrm{p}}$ is the penetration depth of the evanescent wave in the sample.

The amplitude is greatest at the IRE surface (Figure 1). This means that the largest contribution to the spectrum obtained by the MIR technique is from material at or near the surface of the sample in contact with an IRE. For this reason, the FTIR-MIR technique is ideal for surface and interface studies.

The penetration depth, $d_{\mathrm{p}}$, which is defined as the distance required for the electric field amplitude to fall to $e^{-1}$ of its value at the surface, is given by (29):

$$
d_{p}=\frac{\gamma}{2 \pi n_{1}\left[\sin ^{2} \phi-\left(\frac{n_{2}}{n_{1}}\right)^{2}\right]^{\frac{1}{2}}}
$$

where

$\gamma$ is the wavelength in vacuum,

$\mathrm{n}_{1}$ is the refractive index of the IRE,

$\mathrm{n}_{2}$ is the refractive index of the sample, and

$\phi$ is the angle of incidence.

Equation 2 explicitly describes the characteristics of internal reflection spectroscopy. That is, the penetration depth of the evanescent wave in the sample is a function of the angle of incidence, the infrared radiation wavelength, and the refractive indices of the IRE and the sample. $d_{p}$ is a useful parameter for quantitative studies because the majority of the signal derives from this and lesser depths (32) and because it is easily determined.

When an infrared absorbing material is in contact with the IRE, the evanescent wave interacts 
with the material and causes the attenuation of the total reflection of the propagating infrared beam inside the IRE. Detection of the attenuated radiation leaving the IRE yields an IR spectrum of the sample. For thin films, an MIR spectrum is similar to that obtained by the ordinary transmission technique. However, for thick films $(>0.1 \mu \mathrm{m})$, strong absorption bands tend to be distorted and shifted, particularly at long wavelengths. For films thicker than $d_{\mathrm{p}}$, MIR band intensity is independent of film thickness. One can use single or multiple-reflection IRE depending on the application.

The application of FTIR-MIR to studies of thin films on substrates has been reviewed (30, $33,34)$. The use of this technique for extracting information from the polymer/metal interfacial regions has also been reported $(35,36)$. On the other hand, infrared spectroscopy has been the most useful and common method for studying water in materials because of the strong infrared absorptivity of water molecules $(37,38)$. The development of the Fourier transform infrared spectrometer greatly enhanced the speed and sensitivity of infrared spectroscopy. The combination of strong infrared absorptivity of water molecules, the chemical specificity of infrared spectroscopy, and the sensitivity of FTIR spectroscopy in the multiple internal reflection mode makes FTIR-MIR a valuable method for studying water on surfaces, specifically at the asphalt/aggregate interface.

It has been contended that FTIR-MIR is not a true surface technique since the evanescent wave penetrates $0.2-1 \mu \mathrm{m}$ into the material examined. For studies of water at the asphalt/aggregate interface, this is not a problem. First, for the water $\mathrm{OH}$ stretching band $(\sim 2.94 \mu \mathrm{m})$, the penetration depth of the evanescent wave in the asphalt and water on a silicon MIR element is $<0.25 \mu \mathrm{m}$ (as shown later in the Results Section). Of this depth, the majority of the signal comes from half of that thickness because of the rapid decay of the evanescent wave (32). Thus, for a wavelength of $2.94 \mu \mathrm{m}$, the majority of the signal detected is derived from the water material in the depth of $<0.13 \mu \mathrm{m}$ from the asphalt/aggregate interface. Any water detected may thus be considered to be at or near the asphalt/aggregate interface. Further, the water absorbed in the asphalt within the probing depth, though in very small quantity, will be quantified and subtracted from the total detected water.

\section{EXPERIMENTAL SECTION}

\subsection{Materials}

\subsubsection{Asphalts}

Five Strategic Highway Research Program (SHRP) straight core asphalts: AAC-1 (AC-8), AAD1 (AR-4000), AAG-1 (AR-4000), AAK-1 (AC-30), and AAM-1 (AC-20) were used for this study. They were selected based on their differences in adsorption and absorption characteristics, dispersibility (or compatibility), asphaltene contents, and heteroatomic nonhydrocarbon constituents (e.g., N and S), as suggested by Dr. C. W. Curtis of Auburn University and Dr. J. F. Branthaver of Western Research Institute. Some selected properties of these asphalts are shown in Table 1. 
Table 1. Some properties of five core SHRP straight asphalts selected for the study (from Ref. 39)

\begin{tabular}{lcccccc} 
SHRP & \multicolumn{2}{c}{ Asphaltene (heptane) } & \multicolumn{2}{c}{ Element, Wt \% } & Viscosity \\
Asphalt & content, \% & compat. index & $\mathrm{N}$ & $\mathrm{O}$ & $\mathrm{S}$ & poise, 25 \\
\hline AAC-1 & 9.8 & 2.40 & 0.7 & 0.9 & 1.9 & 945,400 \\
AAD-1 & 20.2 & 1.44 & 0.8 & 0.9 & 6.9 & 405,700 \\
AAG-1 & 5.0 & 3.97 & 1.1 & 1.1 & 1.3 & $3,540,000$ \\
AAK-1 & 20.1 & 1.22 & 0.7 & 0.8 & 6.4 & $1,077,000$ \\
AAM-1 & 3.7 & 5.93 & 0.6 & 0.5 & 1.2 & $1,123,000$
\end{tabular}

\subsubsection{Aggregates}

The model aggregates used in this study were $50 \times 10 \times 3 \mathrm{~mm}$ spectroscopic grade, $45^{\circ}$ parallelogram silicon ( $\mathrm{Si}$ ) internal reflection elements (IRE). This aggregate configuration produces 17 reflections within the IRE before exiting. The as-received Si IREs have a 2.07-nm thick layer of native oxide $\left(\mathrm{SiO}_{2}\right.$, refractive index $\left.=1.46\right)$ on their surfaces as measured by ellipsometry. The $\mathrm{SiO}_{2}$-covered silicon $\left(\mathrm{SiO}_{2}-\mathrm{Si}\right) \mathrm{IREs}$ were exposed for two days at $24^{\circ} \mathrm{C}$ and $50 \%$ relative humidity to provide $\mathrm{SiO}_{2}-\mathrm{Si}$ aggregate having surface functional groups similar to those on the surface of siliceous aggregates before mixing with asphalts. The key characteristic of the $\mathrm{SiO}_{2}$ surface is that it reacts readily with water so that at ordinary temperature the $\mathrm{SiO}_{2}$ surface is covered with silanol groups $(\mathrm{SiOH})$. Since this group is very energetic and hygroscopic, it was assumed that some sorbed water was present on the $\mathrm{SiO}_{2}-\mathrm{Si}$ aggregate surfaces before the asphalts were applied. Thus, the surfaces of the model siliceous aggregates used in this study probably had the following chemical structure $(40,41)$ :

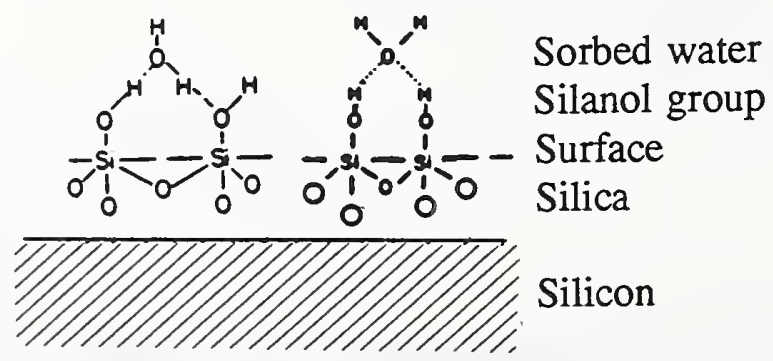

This is a typical hydrated, siliceous surface. There was no attempt to determine the amount of adsorbed water on the model siliceous aggregate surface in this study. The physically-adsorbed water can be removed by degassing at room temperature but the silanol groups only start to condense and eliminate water at about $170^{\circ} \mathrm{C}(41)$. This dehydration is reversible up to $400^{\circ} \mathrm{C}$. The hydrated, $50 \times 10 \times 3 \mathrm{~mm}, 45^{\circ}$, parallelogram $\mathrm{SiO}_{2}$-covered, $\mathrm{Si}$ IRE used in the study is designated as the model siliceous aggregate. 


\subsection{Specimen Preparations}

Specimen configuration (asphalt-coated model aggregate) and experimental set up are illustrated in Figure 2. Asphalts were heated to $60^{\circ} \mathrm{C}$ (in air) and coated on the model siliceous aggregate using a "drawdown" technique (asphalt was cast on the aggregate by pulling a warm glass rod along the length of the aggregate). Two masking tape strips, $1 \mathrm{~mm}$ wide, placed along the length of the model aggregate edges, were used to control the asphalt thickness. After the asphalt application, the $1-\mathrm{mm}$ tape strips were removed and the tape-removed areas were covered with asphalt. Immediately after the asphalt was applied on the aggregate, a transparent water chamber was attached to the asphalt side of the coated-model aggregate specimens. The water chambers were made by pouring a room-temperature-cured epoxy compound into a mold made of silicone adhesive. The rectangular, box-like, $1.5-\mathrm{mm}$ wall chamber was the same length and width as the IRE, i.e. $50 \times 10 \mathrm{~mm}$, and a height of $5 \mathrm{~mm}$. The chamber was closed on five sides and contained an inlet and an outlet to introduce and remove water. The asphalt-coated specimen, which had the water chamber attached to it, was then placed in an MIR accessory holder (Figure 2).

The thickness of the asphalt around the edges of the aggregate substrate (where the masking tape strips were removed and the walls of the water chamber were to be attached) was substantially increased. This was to ensure that the only pathway for migration of water from the chamber to the asphalt/aggregate interface was through the asphalt layer within the walls of the water chamber. To ensure that no water leaked through the specimen during the in situ measurement, a room temperature silicone adhesive was applied around the outside edges of the water chamber. The silicone compound was on the outer surface of the asphalt should not interfere with the spectra obtained because the MIR technique only probes material very close to the asphalt/aggregate interface.

The thickness of the asphalt layer on the model aggregate for the water in situ measurement experiment could not be measured directly. Rather it was deduced from measurements on specimens of one of the SHRP asphalts applied on six glass slides. The glass slides were coated using the same application and thickness-control procedures as those used for asphalts on the model siliceous aggregate. By using only one of the five asphalts for the thickness measurement, we assumed that the thickness of the asphalt layer on the model aggregate was the same for all five SHRP asphalts. This assumption was based on the facts that all five asphalts used were straight asphalts and applied under the same conditions. Prior to thickness measurement, asphalt-coated glass specimens were chilled in a refrigerator $\left(4^{\circ} \mathrm{C}\right)$ for one hour to harden the asphalt. This was done to prevent a possible penetration by the micrometer bar into the asphalt during the measurement. The thicknesses of the uncoated and asphalt-coated glass slides were measured, and the thickness of the asphalt layer was the difference between the two values. Two measurements were made for each asphalt-coated glass specimen. The thickness reported was the average of 12 measurements.

For the FTIR-MIR analysis of five SHRP asphalts on the model siliceous aggregate before exposure to water, a new set of five specimens was prepared. These specimens were made by 
heating the asphalt to $60^{\circ} \mathrm{C}$ then coating on the entire model aggregate surface $(50 \mathrm{~mm} \times 10 \mathrm{~mm})$ without using the $1-\mathrm{mm}$ wide masking tape strips for thickness control. The tape may leave behind some adhesive on the model aggregate surface. This would produce undesirable features in the spectra of the asphalts on model aggregate specimens.

\subsection{Measurement of Water at the Asphalt/Model Siliceous Aggregate Interface}

In situ measurement of water at the asphalt/model aggregate interface was performed using FTIR-MIR spectroscopy. The spectrometer was equipped with a triglycine sulfate detector, a MIR accessory, and a laser reference interferometer to insure wavelength accuracy. The spectrum of the environment in the spectrometer was first taken; this is the background spectrum. Each background spectrum was collected for each asphalt-coated specimen. The MIR accessory that included the water chamber-mounted specimen assembly was then placed in the spectrometer. The spectrum of the specimen in the spectrometer before exposure to water was then collected. This spectrum contained information of both the spectrometer environment and the specimen. Ratioing this spectrum against that of the background produced the spectrum of the specimen. This is the spectrum of the asphalt on the model siliceous aggregate before exposure to water (unexposed). An FTIR-MIR spectrum of the unexposed specimen was taken for each of the five SHRP asphalts.

The chamber (water) was then completely filled by syringe injection with distilled water. The inlet and outlet of the chamber were then sealed to prevent water evaporation. Spectra of the water-exposed (exposed) specimens were taken automatically every hour until the experiment was complete. There were no disturbances to the spectrometer or to the specimens throughout the experiment. The spectrum of the specimen exposed to water at each time interval was then ratioed against the background spectrum. This produced the spectrum of the asphalt-coated specimen which was exposed to water at a particular exposure time. The spectrum of the unexposed specimen was then subtracted from that of the corresponding exposed specimen. The resultant spectrum (difference spectrum) showed only the effect of water on the asphalt-coated specimen. By taking spectra at all exposure times, changes of water pickup as a function of exposure time for each specimen were obtained. All spectra were the result of 32 coadditions and were collected at a $4 \mathrm{~cm}^{-1}$ resolution throughout the $1200-4000 \mathrm{~cm}^{-1}$ range. Unpolarized light at an incident angle of $45^{\circ}$ was used. All spectra were plotted in the absorbance (A) mode. Quantitative analyses were performed using the peak height method, which measures the absorbance at the maximum of the bands of interest.

Since this was an in situ measurement, no errors due to the accessory adjustment, specimen changing, spectrometer and environmental chamber conditions, and optical realignments were introduced in obtaining the spectra. Thus, any changes in the spectra were a direct result of the effect of water entering the asphalt/aggregate specimen. Further, because the asphalt was applied directly to the MIR element, errors resulting from variations in the contact between them were avoided. Until now, lack of control of the contact between the sample and the element has hindered the use of the FTIR-MIR technique for quantitative studies. 
To translate FTIR-MIR spectral intensity into quantitative data for water at the asphalt/aggregate interface, the two additional experiments described in Sections 3.4 and 3.5 were performed.

\subsection{Establishment of a Concentration-Intensity Calibration Curve for Water}

The first experiment was an FTIR-MIR analysis of eight different $\mathrm{H}_{2} \mathrm{O}$ concentrations (w/w) in solution in $\mathrm{D}_{2} \mathrm{O}$. This study was done to establish an FTIR-MIR intensity-concentration curve for water. The water chamber was filled with each water $/ \mathrm{D}_{2} \mathrm{O}$ solution and FTIR-MIR spectra were taken using the same procedure as used for exposed specimens, except that there was no asphalt film on the $\mathrm{SiO}_{2}$-Si IRE. Distilled water and reagent grade $\mathrm{D}_{2} \mathrm{O}$ were used.

\subsection{Water Absorption Measurements of SHRP Asphalts}

Another experiment was a water absorption study of the five SHRP asphalts using the gravimetric method. This test was to determine the amount of water absorbed in the asphalts from only one face of the asphalt film as a function of time. The one-face absorption experiment simulates the absorption process of water in the specimens used for FTIR-MIR measurement of water at the asphalt/aggregate interface. Asphalts were heated to $60^{\circ} \mathrm{C}$ and asphalt films of approximately $60 \mu \mathrm{m}$ thickness were coated onto $50 \times 50 \times 0.5 \mathrm{~mm}$ aluminum plates using the same draw down and thickness-control techniques as used for asphalt films on the model aggregate. Each aluminum plate was weighed before it was coated with the asphalt. The thicknesses of the asphalt films were in the same range as those used for the in situ measurement of water at the asphalt/model siliceous aggregate interface. The reason for using the same thickness in the two experiments is that water absorption in asphalt is a surface phenomenon (42). Any deviation in the asphalt thickness might result in a difference in water absorption behavior. After storage for two days under ambient conditions $\left(24^{\circ} \mathrm{C}\right.$ and $\left.50 \% \mathrm{RH}\right)$, all asphalt-coated aluminum specimens were weighed. Each specimen was then immersed horizontally in a separate glass petri dish filled with distilled water. Specimens were taken out, blotted, and reweighed at specified time intervals. All weighing was carried out to the nearest $1 / 100,000 \mathrm{~g}$ using an analytical balance. Three specimens for each of the five SHRP asphalts were used. The percent water absorption in the asphalt was calculated from the expression:

Water absorption $(\%)=\frac{\text { asphalt wet weight }- \text { asphalt initial weight }}{\text { asphalt initial weight }} \times 100$

\section{RESULTS}

\subsection{FTIR-MIR Analysis of SHRP Asphalts before Water Exposure}

In order to follow changes caused by water entering the asphalt/aggregate interface, it was necessary to examine the FTIR-MIR characteristics of the asphalt/model aggregate system before water exposure. This is because MIR spectra are often different from transmission spectra. 
This difference, particularly for thick films, is due to the matching of the material and IRE indices, and other factors inherent in the MIR technique.

FTIR-MIR spectra in the $1200-4000 \mathrm{~cm}^{-1}$ range of the five SHRP core asphalts on an $\mathrm{SiO}_{2}$ covered Si model aggregate are presented in Figure 3a. The expanded spectra in the 1200-1800 $\mathrm{cm}^{-1}$ region are illustrated in Figure $3 \mathrm{~b}$. Because an Si IRE absorbs strongly in the region below $1200 \mathrm{~cm}^{-1}$, infrared bands below this frequency are deemed not reliable for analysis and therefore not included. These spectra were obtained by ratioing the spectra of the unexposed, asphalt-coated $\mathrm{SiO}_{2}$-Si IRE against those of the corresponding asphalt-free $\mathrm{SiO}_{2}$-SilRE. This procedure eliminated the effects of both the substrate and the spectrometer environment on the spectra. Thus, these spectra contain only the information of the asphalts near the asphalt/model siliceous aggregate. The spectra were collected from specimens prepared without using the masking tape strips. The thickness of the asphalt films for these specimens was $>100 \mu \mathrm{m}$. Beyond the penetration depth of the evanescent wave, which is in the 0.2-1 $\mu \mathrm{m}$ range for asphalt, MIR spectral characteristics are independent of film thickness.

Apart from the absolute intensities of various bands, FTIR-MIR spectra of unexposed AAC-1, AAD-1, AAG-1, AAK-1, and AAM-1 asphalts show similar features. The two strongest bands at 2922 and $2852 \mathrm{~cm}^{-1}$ are due to asymmetric and symmetric $\mathrm{CH}$ stretchings of the $\mathrm{CH}_{2}$ groups of the aliphatic hydrocarbon chains. The intensities of these two bands are highest in AAC-1 and AAM-1, indicating that these two asphalts contain the most aliphatic components among the five SHRP asphalts studied. These results appear to be consistent with data of Reference 39 which reported a $\mathrm{H}$ content of $11.3 \%$ for AAC- 1 and $11.4 \%$ for AAM-1 as compared to 10.8 , 10.5 and $10.2 \%$ for AAD-1, AAG-1 and AAK-1, respectively. The shoulder near $2960 \mathrm{~cm}^{-1}$ is due to asymmetric $\mathrm{CH}$ stretching from the $\mathrm{CH}_{3}$ groups.

The band near $1690 \mathrm{~cm}^{-1}$, which appeared least pronounced for AAC-1 and AAK-1 asphalts, is due to the $\mathrm{C}=\mathrm{O}$ groups of ketones and aldehydes. The band at $1741 \mathrm{~cm}^{-1}$, which was most pronounced in AAM-1 (Figure 3b), is probably due to $\mathrm{C}=\mathrm{O}$ of the esters or their derivatives (43). Note that in the progress report of this project, we reported a relatively strong band at $1719 \mathrm{~cm}^{-1}$, due to the $\mathrm{C}=\mathrm{O}$ groups. This band was from the adhesive left behind on the aggregate after the $1-\mathrm{mm}$ tape strips were removed. This was verified by FTIR-MIR analysis of a specimen in which the masking tape was pressed on a $\mathrm{SiO}_{2}-\mathrm{Si} \mathrm{IRE}$, heated to $60^{\circ} \mathrm{C}$, and then removed. The spectrum of this specimen showed a very strong band at $1719 \mathrm{~cm}^{-1}$. The presence of the adhesive compound on the model aggregate should not affect the water measurements at the asphalt/aggregate interface. This is because the tape resided on only 1-mm wide along the two edges of the aggregate, which were underneath the outside edges of the wall of the water chamber ( $1.5 \mathrm{~mm}$ thick). On the other hand, water migrated through the asphalt area within the inside walls of the water chamber.

The band near $1598 \mathrm{~cm}^{-1}$ is due to $\mathrm{C}=\mathrm{C}$ stretching of the aromatics. The intensity of this band was highest in AAG-1 (Figure 3b). This suggests that this asphalt contained the most aromatic components among the five asphalts. These results agreed with the data of Reference 39 which showed a relatively high $\mathrm{C}$ content and a relatively low $\mathrm{H}$ content. The two-peak bands (Figure 
3b) near $1460 \mathrm{~cm}^{-1}$ are due to the $\mathrm{CH}$ bendings of the aliphatic components of the asphalts. The band at $1460 \mathrm{~cm}^{-1}$ is probably due to the $\mathrm{CH}$ of the $\mathrm{CH}_{2}$ group and the lower frequency band at $1454 \mathrm{~cm}^{-1}$ is probably due to the asymmetric $\mathrm{CH}$ of the $\mathrm{C}-\mathrm{CH}_{3}$ groups $(43,44)$. The band at $1375 \mathrm{~cm}^{-1}$ is due to the symmetric $\mathrm{CH}$ bending of the $\mathrm{C}-\mathrm{CH}_{3}$ groups. There was little evidence of IR absorption in the $3100-3500 \mathrm{~cm}^{-1}$ range, due to $\mathrm{OH}$ and $\mathrm{NH}$ stretchings. This is probably due to the combination of low concentration of these groups in the asphalts and the shallow probing depth of the MIR technique in this frequency region.

Extreme care must be exercised when using these spectra for deducing information on the molecular behavior of asphalts at the asphalt/siliceous aggregate interface because the MIR technique probes rather deep in the asphalt as shown later in Section 4.4. For studies of asphalt/aggregate interface and interphase, asphalt films of $<100 \mathrm{~nm}$ should be used. More detailed analysis of the unexposed spectra of SHRP core asphalts is beyond the scope of the present study.

\subsection{FTIR-MIR Analysis of Asphalt/Model Siliceous Aggregate in Water}

Figures $4 \mathrm{a}$ and $4 \mathrm{~b}$ present two examples of a series of unprocessed FTIR-MIR spectra for two of the SHRP asphalts on the model siliceous aggregate exposed to water for several time intervals. The thicknesses of the asphalt layer for these specimens was approximately $63 \pm 13$ $\mu \mathrm{m}$. These spectra were obtained by ratioing the spectra of the exposed specimens against the corresponding spectra of the background as described in the experimental section. Although the effect of water can be clearly seen, e.g., in the $3100-3500 \mathrm{~cm}^{-1}$ region, these spectra still contain information from the asphalts. To accentuate the effect of water, difference spectra were acquired and these are presented in Figures $5 \mathrm{a}$ to $5 \mathrm{e}$ for the five SHRP core asphalts, AAC-1, AAD-1, AAG-1, AAK-1, and AAM-1, respectively. The difference spectra were obtained by directly subtracting the spectrum of the unexposed, asphalt-coated specimen from that of the corresponding exposed specimen, as discussed in the experimental section, for each of the five SHRP asphalts. The substraction was done after normalizing for the baseline shift. As emphasized earlier, there were no mirror or sample adjustments throughout the duration of the experiment. If there were no effect of the exposed water, all difference spectra (Figure 5) would be straight baselines, with the exception of the intensity fluctuations due to the $\mathrm{CO}_{2}$ bands from the air in the spectrometer. Bands above and below the baseline of a difference spectrum indicate an increase and a decrease, respectively, of the concentration of a chemical functional group as a result of exposure.

Figure 5 shows that the intensities of the bands around 3400 and $1640 \mathrm{~cm}^{-1}$ increased, and the intensities of other bands associated with the asphalts (e.g. $2922 \mathrm{~cm}^{-1}$ ) decreased, as a function of exposure time. These changes in intensity are the result of the water molecules entering the asphalt/aggregate "interfacial region" (defined later in the Depth of FTIR-MIR Probing at the Asphalt/Aggregate Interface Section) and interacting with the evanescent wave. The water bands were verified by the spectrum shown in Figure 6 . This is an FTIR-MIR spectrum of doublydistilled liquid water obtained using the same procedure as that described for asphalt-coated specimens exposed to water, except that there was no asphalt film on the model aggregate. It 
can be seen that the positive bands of the difference spectra have almost the same band shapes and frequencies as those in the liquid water spectrum.

The precise interpretation of IR spectra of liquid water, particularly in the stretching region, is quite difficult owing to 1) different structures, types and degrees of bonding, and 2) considerable overlap between the bending overtone and the stretching vibrations $(37,45,46)$. This difficulty is magnified for water adsorbed on substrates. However, studies by laser-Raman and IR spectroscopies of water in $\mathrm{D}_{2} \mathrm{O}$ and at high temperatures (37) have helped to resolve certain bands. Liquid water generally exhibits a broad band, which peaks around $3400 \mathrm{~cm}^{-1}$, due to the hydrogen-bonded $\mathrm{H}-\mathrm{O}-\mathrm{H}$ stretching. The band at $1640 \mathrm{~cm}^{-1}$ is due to $\mathrm{H}-\mathrm{O}-\mathrm{H}$ bending $(37,45)$. The band which results in a shoulder on the right side (around $3250 \mathrm{~cm}^{-1}$ ) of the water stretching band is assigned to the contribution of the overtone of the bending mode at $1640 \mathrm{~cm}^{-1}$, as theoretically proved (47). Careful examination of the water spectrum in Figure 6 also reveals a very weak shoulder at around $3625 \mathrm{~cm}^{-1}$, which is believed to be due to the non-hydrogen bonded $\mathrm{O}-\mathrm{H}$ stretching of water (37). Liquid water at room temperature contains from 6 to $50 \%$ non-bonded molecules (depending on the method of study) (46). However, because nonbonded $\mathrm{OH}$ is about one order of magnitude less effective in absorbing infrared radiation than hydrogen-bonded $\mathrm{OH}$, the shoulder around $3625 \mathrm{~cm}^{-1}$ in Figure 6 is very small.

Figures 7a-7e are plots of the intensity (peak height) changes of water $\mathrm{OH}$ stretching band as a function of the exposure time for the five SHRP asphalts. Although some data were lost (due to power outages) in $A A D-1$ and $A A K-1$ specimens, the trends of water pickup in these specimens are clear. Except for the AAD-1 asphalt, which did not appear to take up any more water after 50 hours, all other asphalts continued to pick up water for more than 100 hours. Water initially entered the asphalt/aggregate interfacial region at a high rate, but then slowed down. The rates at which water entered the interfacial region were quite different for the five asphalts. The decreases of intensity of the asphalt bands also followed the same trend; one example of which is shown in Figures $8 \mathrm{a}-8 \mathrm{e}$ for the $\mathrm{CH}$ band at $2922 \mathrm{~cm}^{-1}$.

It is interesting that a new, very broad band centered around $2090 \mathrm{~cm}^{-1}$, which was most pronounced for AAD-1 asphalt after prolonged exposure, also increased in intensity with time. The exact nature of the chemical species responsible for this band is not known. However, this region has been assigned to the $-\mathrm{C}=\mathrm{N}^{+}=\mathrm{N}^{-}$- functional group $(43,48)$, suggesting that this group may be one of the main components of water soluble products formed when asphalts are immersed in water.

\subsection{Water Concentration-Intensity Calibration Curve}

In order to translate the FTIR intensity shown in Figure 7 to the water amount, a concentrationintensity correlation for water using the same analytical technique must be established. This was accomplished using water at different concentrations in solution in $\mathrm{D}_{2} \mathrm{O}$. Figure 9 depicts FTIRMIR spectra of water at eight concentrations in $\mathrm{D}_{2} \mathrm{O}$. It is noted that when $\mathrm{H}_{2} \mathrm{O}$ and $\mathrm{D}_{2} \mathrm{O}$ are mixed, $\mathrm{HDO}$ is formed and the solutions contain $\mathrm{HDO}, \mathrm{H}_{2} \mathrm{O}$ and $\mathrm{D}_{2} \mathrm{O}$. Accordingly, the FTIRMIR spectra will contain contributions from H-O-H, D-O-D and D-O-H bonds. Since, for every 
two H-O-D molecules formed, one molecule of water is consumed, the intensity of the $\mathrm{OH}$ group in the spectra should be proportional to the concentration of water in the $\mathrm{D}_{2} \mathrm{O}$ solutions. Any deviation from this proportionality may be due to factors other than the mixing of the two solutions, e.g, degrees of bonding.

The bands near 3400 and $1640 \mathrm{~cm}^{-1}$ are due to water, as discussed earlier, while those near 2520 and $1210 \mathrm{~cm}^{-1}$ are due to $\mathrm{D}_{2} \mathrm{O}$ molecules. The $\mathrm{OH}$ stretching bands for water concentrations from 5 to $35 \%$ are mostly symmetrical, while those at higher concentrations are not. On the other hand, the $\mathrm{OH}$ bending at $1640 \mathrm{~cm}^{-1}$ only becomes visible at water concentrations $>20 \%$, indicating that this band was not useful for detecting water at low concentrations. Further, the shoulder at lower frequency of the $\mathrm{OH}$ stretching, which is barely visible at $50 \%$, becomes very pronounced at 75 and $100 \%$ water concentrations. For these reasons, peak height (instead of peak area) of the $\mathrm{OH}$ stretching band (instead of the $\mathrm{OH}$ bending band) was selected for the quantitative analysis. Figure 10 presents the FTIR-MIR intensity changes of the water $\mathrm{OH}$ stretching band as a function of water concentration. It is obvious that the FTIR-MIR intensityconcentration relationship for water does not follow the well-known linear Beer-Lambert law. The deviation is larger near the highest water concentrations. Figure 10 was used for determining the total amount of water detected by the FTIR-MIR technique.

\subsection{Depth of FTIR-MIR Probing at the Asphalt/Siliceous Aggregate Interface}

The FTIR-MIR technique was able to detect water that had entered the asphalt-coated model aggregate specimens. The major question is: Where in the specimen was the water with which the water bands were associated? For example, were they from water absorbed in the asphalt, or from water adsorbed at the asphalt/model aggregate interface or both? To answer these questions, we made calculations to determine the penetration depth of the evanescent wave, $d_{p}$, into the water and the asphalt as a function of wavelength using the theory of internal reflection spectroscopy (Equation 2). Figure 11 shows these results. The calculations were made using a value of 3.42 for the refractive index of a silicon substrate because the $\mathrm{SiO}_{2}$ film was too thin to have an effect on $d_{\mathrm{p}}$. The refractive index of asphalt was taken as 1.55 , calculated from the data in Reference (49), and the angle of incidence was at $45^{\circ}$. As can be seen from Figure 11 that the MIR technique can probe rather deeply into asphalt, particularly at longer wavelengths of $\mathrm{IR}$ radiation. The results also show that $d_{\mathrm{p}}$ in asphalts is slightly greater than in water; this difference is greater at longer wavelengths. At $2.94 \mu \mathrm{m}$ wavelength $\left(3400 \mathrm{~cm}^{-1}\right.$, the $\mathrm{OH}$ stretch of water), $d_{\mathrm{p}}$ values in water and asphalt are 0.225 and $0.243 \mu \mathrm{m}$, respectively. At this wavelength, there is only a small difference $(.018 \mu \mathrm{m})$ in the $d_{\mathrm{p}}$ values whether asphalt or water is in the interfacial region. Due to exponential decay of the signal, $d_{\mathrm{p}} / 2$ has been suggested as a better indication of the depth of the surface layer probed by the MIR technique than $d_{\mathrm{p}}(32)$. Regardless of the choice, the water signals observed in Figure 5 must be from water very close to the asphalt/model aggregate interface. The region of thickness $d_{\mathrm{p}}$ close to the interface where water is detected is defined here as the "interfacial region". 


\subsection{Water Absorption Characteristics of SHRP Asphalts}

The total water detected in the interfacial region is the sum of the water absorbed in the asphalt within $d_{\mathrm{p}}$ and of the water layer at the asphalt/aggregate interface. By accounting for the former, the amount and thickness of the water at the asphalt/aggregate interface can be calculated.

The amount of water in asphalt within $d_{\mathrm{p}}$ was determined based on the water absorption experiment using asphalt-coated aluminum specimens. The amounts of water taken up by the five SHRP core asphalts as a function of exposure time are presented in Figure 12. Figure 12 also gave the standard deviations for each data point. It is apparent that the standard deviations for the specimens of the AAC-1 and AAK-1 asphalts were greater than those of the other three asphalts. It is not known whether the large variations in AAC-1 and AAK-1 asphalts were due to inhomogeneity of the specimens (e.g. due to poor flow at $60^{\circ} \mathrm{C}$ ) or due to random experimental errors in the blotting and weighing procedures. After 300 hours, AAD-1, AAC-1, and AAK-1 asphalts picked up the most water, nearly $6 \%$; AAM-1 absorbed the least, $1.2 \%$, and AAG-1 took up around 2\%. An interesting observation was that the asphalts that absorbed the most water tended to have the highest asphaltene (heptane) and S contents, and lowest compatibility indices, while those that picked up the least water had low asphaltene and $S$ contents, and high compatibility indices (see Table 1). These results suggest that these three properties may be related to the water absorption characteristics of asphalts. Further studies are required to verify this postulation.

An uncertainty from the water absorption data is that if water accumulated at the asphalt/aluminum interface, the weight gain would include this water. However, if such were the case, it would introduce less than $1 \%$ in the amount of water at the asphalt/aggregate interface determined by the FTIR-MIR technique. This is because the water absorption of the asphalt is small ( $<4 \%$ based on the asphalt, over the times used for the FTIR measurements). When the amount of water absorbed is based on the amount of asphalt in $d_{p}$, this value becomes negligibly small. For example, a maximum $4 \%$ of water in the asphalt volume of $47 \times 7 \mathrm{~mm}$ (dimensions of the water chamber) $\times 0.243 \times 10^{-3} \mathrm{~mm}\left(d_{\mathrm{p}}\right.$ in asphalt) yields a water quantity of only $3.35 \times 10^{-8} \mathrm{~g}$ (calculation using asphalt density of $1.001 \mathrm{Mg} / \mathrm{m}^{3}$ ). As will be seen later, this value is two orders of magnitude smaller than that for the total water detected. Thus, a variation of the water absorption value (due to water adsorption at the asphalt/aluminum interface) has a negligible effect on the values of water at the asphalt/model aggregate interface.

Visual observation of all five SHRP core asphalts studied after the water immersion test revealed that their surface appearances were quite different. Before exposure, all five asphalts were black (Figure 13a) and their surfaces were similar and appeared featureless to the naked eye or under a light microscope at any magnification. After exposure (1075 hours), the AAD-1 and AAK-1 asphalts appeared grey, AAC-1 and AAM-1 remained black (Figure 13b) and AAG-1 was dark brown (not distinguishable in Figure 13b). It was noticed that AAD-1 and AAK-1 started to change color at about 50 hours of exposure. This corresponds to the start of the faster water absorption rates in these two asphalts (Figure 12). 
Light microscopy studies of the specimens after being immersed in water for 1075 hours followed by blowing with dried air (to remove excess water on the specimen surfaces) showed that the surfaces of the exposed AAK-1 and AAD-1 asphalts had a highly-textured microstructure as seen in Figures 14a and 14b, respectively. Apparently, some form of emulsification took place in these asphalts. The structure of the AAK-1 specimen surface had a finer texture than that of the AAD-1. On the other hand, the surface of AAD-1 had many large holes and craters (Figure 14c). The highly-textured structure only formed on the surface (for the 1075-hour exposure) as the asphalt material underneath the textured layer did not seem to be altered (Figure 14b). It was noted that these two asphalts also absorbed the most water, nearly $6 \%$ after 300 hours exposure as indicated above.

Figure 15 provides examples of surface microstructures of AAC-1, AAG-1, and AAM-1 asphalts after exposure. The surfaces of AAC-1, AAG-1 and AAM-1 asphalts became bumpy, with blunt peaks and flat valleys that resembled the skin of an orange, a phenomenon commonly known as "orange peel" in paints and coatings. The orange-skin appearance of AAG-1 and AAM-1 were apparent and could be clearly seen by the naked eye. The bumpy appearance on the surface of AAC- 1 asphalt was less obvious by the naked eye but could be easily seen by a light microscope at low magnification (Figure 15a). It is noted from Table 1 that these three asphalts have the highest compatibility indices and lowest asphaltene (heptane) and $S$ contents among the five asphalts studied. Further, AAG-1 and AAM-1, the two asphalts which showed the most obvious orange-skin appearance, also have the highest viscosities. The peaks and valleys were probably caused by surface tension gradients and rheological changes during the exposure. Close examination of these three asphalts revealed that their surfaces contained numerous pinholes and bubbles after 1075 hours exposure (e.g. Figure 15a at $6.25 \mathrm{x}$ for AAC-1; Figure 15d at 25x for AAM-1). Before exposure, all the asphalts showed smooth and shiny surfaces. More in depth analysis of the asphalt surfaces after immersion in water was beyond the scope of this study. However, we feel that understanding of the chemical and microstructural changes that occur on the surface of asphalts during exposure to water may provide information relevant to the adhesion of wet pavement to ice, friction with tire, water migration, stripping characteristics, and overall performance of asphalts in wet conditions.

\subsection{Quantitative Measurements of Water at the Asphalt/Model Siliceous Aggregate Interface}

Water at the asphalt/model aggregate interface was quantified by using all the information presented above; that is, the concentration-intensity calibration curve, the water absorption results, and the probing depth data. Water in the asphalt/aggregate interfacial region is the sum of the water absorbed in the asphalt within $d_{\mathrm{p}}$ and of the water layer at the asphalt/substrate interface, as graphically illustrated below 


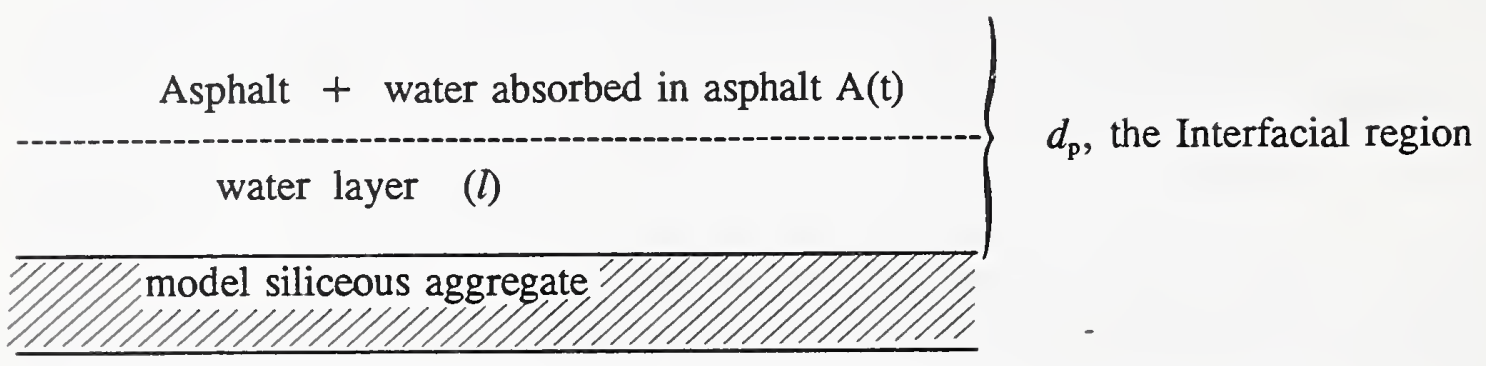

This can be expressed mathematically as:

$$
\begin{gathered}
C_{w}(t)=A(t)[1-x]+x \\
x=\frac{l(t)}{d_{p}(t)} \\
d_{p}(t)=243-18 x
\end{gathered}
$$

where

$\mathrm{C}_{\mathrm{w}}(\mathrm{t})$ is the mass fraction of water within $d_{\mathrm{p}}$ as a function of time $\mathrm{t}$,

$A(t)$ is the mass fraction of water absorbed in the asphalts as a function of time $t$, $\mathrm{x}$ is the thickness fraction of $d_{\mathrm{p}}$ occupied by the water layer at the asphalt/aggregate interface,

$l(\mathrm{t})$ is the thickness of the water layer at the asphalt/aggregate interface, $\mu \mathrm{m}$, and $d_{\mathrm{p}}(\mathrm{t})$ is the penetration depth as a function of time, $\mu \mathrm{m}$.

Equation [5] accounts for the change of $d_{\mathrm{p}}$ due to a replacement of asphalt $\left(d_{\mathrm{p}}=0.243 \mu \mathrm{m}\right)$ by water $\left(d_{\mathrm{p}}=0.225 \mu \mathrm{m}\right)$ during exposure. $\mathrm{C}_{\mathrm{w}}(\mathrm{t})$ was calculated using the experimental data of Figure 7 and concentration-intensity calibration curve given in Figure 9. A(t) (mass fraction of water uptakę against the asphalt film initial weight) was obtained from linear interpolation of the water absorption data for asphalt films on the aluminum plates given in Figure 12.

A computer spreadsheet was designed for the inter-relations shown in Equations 3, 4, and 5 to obtain the thickness, $l(t)$, of the water layer at the asphalt/model aggregate interface for all five SHRP asphalts as a function of exposure time. The results are presented in Figure 16. The thickness values were calculated assuming that water was uniformly distributed on the entire surface area (within the chamber) of the specimen. The mass of water at the asphalt/aggregate interface was then obtained by multiplying the thickness value by the surface area of the 
specimen within the chamber walls $\left(329 \mathrm{~mm}^{2}\right)$ and by a water density of $1 \mathrm{Mg} / \mathrm{m}^{3}$. These results are presented in Figure 17. Alternatively, the mass can be determined first, then converted to a thickness value. Included in Figure 17 is the total mass of water detected in the interfacial region (upper curves). The difference of the upper and lower curves is the mass of water absorbed in the asphalt within $d_{\mathrm{p}}$. As can be seen, the mass of water detected in the asphalt near the interface is very small in comparison with the mass of water at the asphalt/aggregate interface. There are data fluctuations at some exposure times. This is probably due to the baseline shift resulting from changes in the refractive index of the material at the asphalt/model aggregate interface. Another reason may be a partial release of the swelling stress of the water layer at the asphalt/aggregate interface. However, the deviations are very small and do not affect the general trend of the data. Table 2 summarizes the thickness and the mass of water at the asphalt/siliceous aggregate interface at several exposure times.

Table 2. Thickness of the water layer and mass of water at the asphalt/model aggregate interface for five SHRP asphalts at three exposure times

Asphalt $\quad$ Exposure time, hours

\begin{tabular}{|c|c|c|c|c|c|c|}
\hline \multirow[t]{2}{*}{ 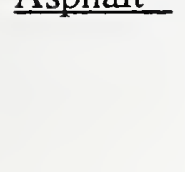 } & \multicolumn{2}{|c|}{10} & \multicolumn{2}{|l|}{50} & \multicolumn{2}{|c|}{90} \\
\hline & $\frac{\text { thickness }}{n m}$ & $\frac{\text { mass }}{\mathrm{gx} \times 10^{-6}}$ & $\frac{\text { thickness }}{\mathrm{nm}}$ & $\frac{\text { mass }}{\mathrm{gx} \times 10^{-6}}$ & $\frac{\text { thickness }}{\mathrm{nm}}$ & $\frac{\text { mass }}{\mathrm{gx} 10^{-6}}$ \\
\hline AAC-1 & 0 & 0 & 20 & 6.6 & 34 & 11.2 \\
\hline AAD-1 & 15 & 4.8 & 88 & 29.1 & 87 & 28.9 \\
\hline AAG-1 & 18 & 6.0 & 28 & 9.4 & 43 & 14.4 \\
\hline AAK-1 & 12 & 3.9 & 24 & 8.0 & 32 & 10.6 \\
\hline AAM-1 & 11 & 3.6 & 21 & 7.1 & 24 & 7.9 \\
\hline
\end{tabular}

Thicknesses of the water layer at the asphalt/model siliceous aggregate interface were different for the five asphalts studied. The thickness of the water layer at the AAD-1/aggregate interface increased rapidly and remained almost constant after 45 hours of immersion, but that for the AAC-1 specimen increased slowly and did not level off even after 100 hours of immersion. Water layers at the interface of AAG-1, AAK-1, and AAM-1 asphalts also increased less rapidly than that for AAD-1 and seemed to slow down after 75 hours. For prolonged immersion, e.g. 90 hours, the water layer at the asphalt/model aggregate interface was thickest for the AAD-1 and thinnest for the AAM-1 asphalts (Table 2). The results suggest that the AAD-1 asphalt/model aggregate bonds were probably less resistant to stripping than those in the AAM-1 asphalt/model aggregate system. It would be necessary to repeat the study using thicker asphalt films to confirm these data. Further, data from water damage tests or bonding tests in the presence of water would have to be obtained and correlated with these data before any definite conclusion about the water susceptibility ranking of these five SHRP asphalts could be made. This will be the main objective of the second phase of the study.

It is expected that this technique could also be used for obtaining similar information on organic 
or inorganic compounds, such as oil or lime, at the interface between an asphaltic or polymeric film and a siliceous aggregate.

\subsection{Apparent Diffusion Coefficients of Water Through SHRP Asphalts on Aggregate}

The technique developed for measuring and quantifying in situ water at the asphalt/aggregate interface detects the water after it has migrated through the asphalt film. Thus, the technique is suitable for determining the apparent diffusion coefficient of water in asphalt. Indeed, the technique is unique for studying the diffusion of water in asphalt or any type of film or layer adhered to a substrate. No such method was previously available. Due to the substrate, the surface composition, and contamination of the substrate, the diffusion characteristics of substances through a film on a substrate may not be the same as that through a detached film of the same material.

From the instant liquid water was admitted to the asphalt side of the asphalt-coated model aggregate and prior to the attainment of a steady state, both the rate of flow and the water concentration at any point of the asphalt layer varied with time. If the diffusion coefficient was constant and the concentration of water at the asphalt/aggregate interface was negligible, the amount of water which passed through the asphalt layer in time $t$ is given by the time lag equation for a permeation experiment (49)

$$
\frac{Q_{w}}{l_{a} C_{1}}=\frac{D t}{l_{a}^{2}}-\frac{1}{6}-\frac{2}{\pi^{2}} \sum_{n=1}^{\infty} \frac{(-1)^{n}}{n^{2}} \exp \left(\frac{-D n^{2} \pi^{2} t}{l_{a}^{2}}\right)
$$

$\mathrm{Q}_{\mathrm{w}}$ is the mass of water which has passed through the asphalt film, in $\mathrm{g}$, $l_{\mathrm{a}}$ is the asphalt film thickness, in cm, $\mathrm{C}_{1}$ is the concentration of water on the outside face of the asphalt coated model aggregate, in $\mathrm{g}$,

$D$ is the apparent diffusion coefficient; if $Q_{w}$ and $C_{1}$ are both expressed of the same quantity, e.g., $g$ or $g$ molecules then $D$ has the unit $\mathrm{cm}^{2} \mathrm{~s}^{-1}$, $t$ is the time, in $s$, and, $\mathrm{n}$ is an integer

As $t \rightarrow \infty$, a steady state is approached and the exponential terms become negligibly small, so that the plot of $Q_{w}$ vs $t$ tends to the line

$$
Q_{w}=\frac{D C_{1}}{l_{a}}\left[t-\frac{l_{a}^{2}}{6 D}\right]
$$

which has an intercept, $t_{\text {in }}$, on the $t$-axis given by 


$$
t_{i n}=\frac{l_{a}^{2}}{6 D}
$$

Apparent diffusion coefficients, D, for AAD-1, AAG-1, and AAK-1 SHRP asphalts were determined using equation [8] where $\mathrm{l}_{\mathrm{a}}$ was $63 \mu \mathrm{m}$, and $\mathrm{t}_{\mathrm{n}}$ values were obtained from the intercepts on the t-axis and the mass-time curves given in Figure 17. Table 3 presents these results; for comparison, Table 3 also includes the diffusion coefficients of several polymers extracted from the literature.

Table 3. Apparent diffusion coefficients of water through SHRP asphalts and some polymeric films

\begin{tabular}{|c|c|c|c|c|}
\hline SHRP Asphalt & $t_{i n}, s$ & $\mathrm{D}, \mathrm{cm}^{2} \mathrm{~s}^{-1}$ & Reference & Remark \\
\hline $\mathrm{AAC}-1$ & 43,500 & $1.4 \times 10^{-10}$ & This work & $\begin{array}{l}\text { FTIR method, } \\
\text { liquid water }\end{array}$ \\
\hline AAD-1 & 25,100 & $2.5 \times 10^{-10}$ & $"$ & $"$ \\
\hline AAK-1 & 20,100 & $3.3 \times 10^{-10}$ & $"$ & $"$ \\
\hline Epoxy Paint & 1,000 & $3.3 \times 10^{-8}$ & Nguyen, 1992 & $"$ \\
\hline Polyethylene & & $230 \times 10^{-9}$ & (49) & $\begin{array}{l}\text { Permeation method } \\
\text { water vapor }\end{array}$ \\
\hline PVC & & $23 \times 10^{-9}$ & (49) & 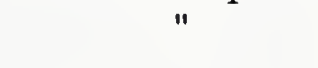 \\
\hline Rubber & & $0.4 \times 10^{-9}$ & (49) & $"$ \\
\hline Polydimethylsil & silicones) & $70,000 \times 10^{-9}$ & (49) & $"$ \\
\hline
\end{tabular}

D only varies by a factor of about two for these three asphalts. No $D$ values for water in asphalts were found in the literature. Calculation of D values for AAG-1 and AAM-1 asphalts was not possible because of difficulty in obtaining their $t_{i n}$ due to the rapid transport of water to the asphalt/aggregate interface for these asphalts (see Figure 17). This suggests these two asphalts have $\mathrm{D}$ values higher than those given in Table 3. Use of thicker asphalt films should alleviate this problem since $t_{\mathrm{in}}$ is proportional to $\mathrm{l}_{\mathrm{a}}^{2}$. In order to derive more reliable $\mathrm{D}$ values from the absorption data given in Figure 12, substantially more data points in the early immersion times would be needed. However, an estimation was made from the AAC- 1 data in Figure 12 , which show that the $\mathrm{D}$ value calculated from the absorption experiment was within 
a factor of about two of the value for the same asphalt given in the above table. The calculation was made using an equation for computing diffusion coefficients from sorption experiment (50) and taking into account that the absorption in this study was from only one face.

It is noted that the diffusion coefficient values for polymers given in Table 3 were for permeation of water vapor through a detached film. These values represent the diffusion through a homogeneous and defect-free polymer matrix of a detached film. The values for liquid water in asphalt and epoxy films obtained by the new technique were for a film attached to a substrate. These diffusion values may be influenced by the effects of inhomogeneity, defects, and water soluble species in the film, as well as the effects of film/substrate interfacial properties. Thus, these values probably better represent the transport of liquid water through common materials than do the values obtained for water vapor transport through a detached film. It is expected that the technique would be applicable to studies of the transport of water, organic, or inorganic liquids through an asphalt/aggregate mixture or concrete layer of any thickness on a substrate.

\subsection{Bond Strength of Asphalt on Aggregate in Water}

To utilize this technique as a nondestructive method for studying the stripping of asphalt, the information obtained must be correlated with results of a bond test in water. No such test is presently available. In preparing for the second phase of this project, we explored the development of such a test; preliminary results are encouraging. The test combines the use of the portable, pneumatic adhesion tester developed at NIST for testing the adhesion of a paint on a substrate and of a special probe developed during the exploratory work. The special probe provides pathways for water transport through the asphalt to the asphalt/aggregate interface; the water weakens the bond between the asphalt and the aggregate as a function of exposure. The preliminary results (Figure 18) for approximately $150 \mu \mathrm{m}$-thick asphalt films on a soda glass substrate showed that, before exposure and after 4-hour water immersion, the bond strength was determined by the cohesive strength of the asphalt. When water reached the interface (about 6 hours), the bond strength decreased and a mixed mode of adhesive and cohesive failure was observed. Continued exposure resulted in further bond strength decrease and only adhesive failure at the asphalt/aggregate interface was observed at 16 hours. At this stage, some water had accumulated at the asphalt/aggregate interface and could be observed by the naked eye. At this time, the bond strengths of the asphalt/soda glass system were much lower than those before exposure. It is noted that the bond tests were performed immediately after the specimens were removed from the water container. However, with the portable pneumatic adhesion tester, the bond strength tests could be conveniently done, both in the lab or in the field, with the specimens still immersed in water. Incidentally, the cohesively-failed surface showed numerous void areas in the asphalt. This may be the least-resistant pathway for water transport to the asphalt/aggregate interface. 


\section{IMPACT ON HIGHWAY TECHNOLOGY}

Besides measuring in-situ water at the asphalt/aggregate interface, the new technique can provide a method for:

1. Evaluating the water susceptibility of different asphalt binders on a siliceous aggregate,

2. Evaluating and screening antistripping agents for asphalts on a siliceous aggregate. (Antistripping agents may be mixed in the asphalt binders or applied on siliceous aggregate surface before hot mixing.)

3. Investigating the effects of aggregate surface contamination, and hot mix and service temperatures, on the build up of the water layer at the asphalt/siliceous aggregate interface,

4. Measuring the diffusion of water through a layer of asphalt to a siliceous surface (essential for stripping modeling),

5. Measuring in situ organic and inorganic compounds at the asphalt/aggregate interface, and,

6. Measuring transport properties of water, organic, and inorganic materials through a layer of asphalt/aggregate mixture or concrete on a substrate.

\section{CONCLUSIONS}

A sensitive technique for measuring water in situ at the asphalt/model siliceous aggregate has been developed. The technique can detect and also provide quantitative information on the water at the asphalt/siliceous aggregate interface. This information will be valuable for understanding and predicting the water susceptibility of asphalt/siliceous aggregate mixtures. The technique is unique in providing information on the transport of liquid water through an asphalt layer of any thickness attached to an aggregate. Such information should be useful for predicting the performance of asphalt and asphalt/aggregate mixtures in water immersion service. The technique should therefore be useful for predicting water susceptibility, studying the effects of the aggregate, contamination of the aggregate, antistripping agents, and the asphalt on the water susceptibility of asphalt/siliceous aggregate mixtures. Further, the technique should be useful for measuring organic or inorganic materials, such as oil, lime, etc., in situ at the asphalt/aggregate interface. Similarly, it may also be useful for measuring the transport properties of water, organic, and inorganic materials through a layer of asphalt/aggregate mixture or concrete on a substrate. It is anticipated that the technique will have a wide range of applications in highway technology. 


\section{Acknowledgements}

The research described herein was supported by the Strategic Highway Research Program (SHRP). SHRP is a unit of the National Research Council that was authorized by Section 128 of the Transportation and Uniform Relocation Assistance Act of 1987.

The publication of this report does not necessarily indicate approval or endorsement of the findings, opinions, conclusions, or recommendations either inferred or specifically expressed herein by the National Academy of Sciences, or the American Association of State Highway and Transportation Officials or its member states. 


\section{REFERENCES}

1. P. Hubbard, Adhesion of Asphalt to Aggregate in the Presence of Water, Proceedings, Highway Research Board, 1938, Vol. 18, Part I, p. 238.

2. The Effect of Water on Bitumen-Aggregate Mixtures, Publication 332, Bibliography 17, Highway Research Board, Washington, DC., 1954.

3. F. C. Gzemski, D. W. McGlashan, and W. L. Dolch, Thermodynamic Aspects of the Stripping Problem, Highway Research Circular No. 78, Highway Research Board, Washington, DC., March, 1968.

4. K. Majidzadeh and F. N. Brovold, State of the Art: Effect of Water on BitumenAggregate Mixtures, Highway Research Board, Special Report 98, 1968, pp 1-62.

5. M. A. Taylor and N. P. Khosla, Stripping of Asphalt Pavements: State of the Art, Transportation Research Record 911, 1983, p. 150.

6. F. Harrigan, New Opportunity for Asphalt Research, Focus, April, 1985, pp. 1-6.

7. D. G. Tunnicliff and R. E. Root, Antistripping Additives in Asphalt Concrete: State of the Art, Asphalt Paving Technol., 51 (1982) 265.

8. W. D. Bascom, Water at the Interface, J. Adhesion, 2 (1970) 168.

9. H. Leidheiser, Jr. and W. Funke, Water Disbondment and Wet Adhesion of Organic Coatings on Metals: A Review and Interpretation, J. Oil and Colour Chemists' Association, 5 (1987) 121.

10. R. Miles, In Situ Characterization of Electrode-Electrolyte Interface Using Spectroscopic Techniques, Surface and Interface Analysis, 5 (1983) 43.

11. A. Bewick and S. Pons, Infrared Spectroscopy of the Electrode-Electrolyte Solution Interface, in Advances in Infrared and Raman Spectroscopy, R. J. H. Clark and R. E. Hester, Eds, Vol. 12, Wiley Heyden, N. Y., 1985, Chapter 1.

12. K. Ashley and S. Pons, Infrared Spectroelectrochemistry, Chem. Rev., 88 (1988) 673.

13 T. Nguyen, E. Byrd, and C. Lin, A Spectroscopic Technique for In Situ Measurements of Water at the Coating/Metal Interface, J. Adhesion Sci. Technol., 5, 697 (1991).

14. T. Nguyen, E. Byrd, C. Lin, and D. Bentz, A Novel Technique for Measurement of Water at the Interface between a Metal and an Opaque Polymeric Film, Advanced Composite Materials, 19, 1051 (1991). 
15. A. C. Zettlemoyer, F. J. Micale, and K. Klier, Adsorption of Water on WellCharacterized Solid Surfaces, in Water, A Comprehensive Treatise, F. Franks, Ed., Plenum Press, N. Y., 1975, Vol.5, Chapter 5.

16. G. Reinhard, Surface Characterization of Iron and Steel Prior to Coating, Progress Organic Coatings, 15 (1987) 125.

17. T. Nguyen and W. E. Byrd, Degradation of Epoxide Coatings on Steel Under a Mild Corrosive Environment, Proc. FATIPEC Congress, Venice, Italy, 1986, Vol. 3, pp 331-367.

18. A. J. Kinloch, Introduction, in Durability of Structural Adhesives, A. J. Kinloch, Ed., Applied Science Publishers, New York, 1983, pp. 1-39.

19. R. A. Gledhill and A. J. Kinloch, Environmental Failure of Structural Adhesive Joints, J. Adhesion, 6 (1974) 1.

20. J. W. McBain and D. G. Hopkins, Adhesives and Adhesive Action, Appendix IV, Second Report of the Adhesive Research Committee, Dept. of Scientific and Industrial Research, London, 1929, p. 34.

21. J. M. Rice, Relationship of Aggregate Characteristics to the Effect of Water on Bituminous Paving Mixtures, American Society for Testing and Materials, STP 240, 1958, p. 17.

22. C. Mack, Physical Chemistry, in Bituminous Materials: Asphalts, Tars and Pitches, A. Hoiberg, Ed., Robert E. Krieger Publishing Company, N.Y., 1979, Vol. 1, pp. 2631.

23. C. W. Curtis, K. Ensley, and J. Epps, SHRP A-003B, Fundamental Properties of Asphalt/Aggregate Interactions Including Adhesion and Absorption, Strategic Highway Research Program, National Research Council, Washington, D.C., Final Report, August, 1991, pp. 3 and M7.

24. H. Karius and J. L. Dalton, Detachment of Stone from Binder Under Influence of Water in Road Surface Dressings, J. Institute of Petroleum, 50 (1964) 1.

25. F. P. Bowden and W. R. Throssell, Adsorption of Water Vapor on Solid Surfaces, Pro. Royal Soc., 209 (1951) 297.

26. J. Comyn, The Relationship between Joint Durability and Water Diffusion, in Developments in Adhesives-2, A. J. Kinloch, Ed., Applied Science Publishers, New Jersey, 1981, pp 279-314. 
27. W. Brockmann, Steel Adherends, in Durability of Structural Adhesives, A. J. Kinloch, Ed., Applied Science Publishers, N.Y., 1983, pp. 281-316.

28. D. M. Brewis, Aluminum Adherends, in Durability of Structural Adhesives, A. J. Kinloch, Ed., Applied Science Publishers, N. Y., 1983, pp. 215-254.

29. N. J. Harrick, Internal Reflection Spectroscopy, Harrick Scientific Corporation, N. Y., 2nd ed., 1979.

30. R. J. Jakobsen, Application of FTIR to Surface Studies, in Fourier Transform Infrared Spectroscopy, Applications to Chemical Systems, J. R. Ferraro and L. J. Basile, Eds., 1979, Vol. 2, pp. 165-191.

31. I. Newton, Opticks, Dover Publications, N.Y. 1952.

32. Iwamoto and K. Ohta, Quantitative Surface Analysis by Fourier Transform Attenuated Total Reflection Infrared Spectroscopy, Applied Spectroscopy, 38 (1984) 359.

33 T. Nguyen, Applications of Fourier Transform Infrared Spectroscopy for Surface and Interface Studies, Progress Organic Coatings, 13 (1985) 1-35.

34. H. Ishida, Quantitative Surface FTIR Spectroscopic Analysis of Polymers, Rubber Chemistry and Technology, 60 (1987) 498-550.

35. H. Leidheiser, Jr., and P.D. Deck, Chemistry of the Metal-Polymer Interfacial Region, Science, 241 (1988) 1176.

36. F. J. Boerio and D. J. Ondrus, Molecular Structure of the Interphase in Aluminum/Epoxy and Copper/Epoxy Adhesive Joints, J. Adhesion, 29 (1989) 27.

37. G. E. Walrafen, Raman and Infrared Spectral Investigations of Water Structure, in Water, A Comprehensive Treatise, F. Franks, Ed, Plenum Press, N.Y., 1972, Vol. 1 , Chapter 5 .

38. L. H. Little, Infrared Spectra of Adsorbed Species, Academic Press, N. Y, 1966.

39. J. F. Branthaver, J. C. Peterson, J. J. Duvall and P. M. Harnsberger, Investigation of Compatibilities of SHRP Asphalts, Paper presented at the TRB Annual Meeting, Washington, D.C., January, 1991.

40. R.K.Iler, The Chemistry of Silica, John Wiley and Sons, N.Y., 1979, Chapter 6, p. 627. 
41. M. L. Hair, Infrared Spectroscopy in Surface Chemistry, Marcell Dekker, Inc, N.Y. 1967, p.85.

42. S. H. Alexander and G. W. Tarver, Permeability and Water Absorption, in Bituminous Materials: Asphalts, Tars, and Pitches, Vol. 2: Asphalts, A. J. Hoiberg, Ed., Robert E. Krieger Publishing Company, N.Y., 1979, pp 223-247.

43. L.J. Bellamy, Infrared Spectra of Complex Molecules, Chapman and Hall, London, 3rd Ed., 1975, pp. 304-306 and references therein.

44. A.A. Christy, B. Dahl, and O.M. Kvalheim, Structural Features of Resins, Asphaltenes, and Kerogen Studied by Diffuse Reflectance Infrared Spectroscopy, Fuel, 68 (1989) 431.

45. D.Eisenberg and W. Kauzmann, The Structure and Properties of Water, Oxford University Press, New York, 1969, pp. 228-253.

46. N.J. Hornung and G.R. Choppin, The Structure of Water and Its Solutions, Appl. Spectrosc. Rev., 68 (1974) 147-181.

47. J.R. Reimers and R. Watts, The structure and Thermodynamic Properties and Infrared Spectra of Liquid Water and Ice, Chemical Phys., 9 (1984) 20.

48. A. Streitwieser, Jr. and C. H. Heathcock, Introduction to Organic Chemistry, Macmillan Publishing Co.,Inc., N.Y., 1976, p. 1201.

49. G. Abson and C. Burton, Physical Tests and Range of Properties, in Bituminous Materials: Asphalts, Tars, and Pitches, Vol. 1: General Aspects, A. J. Holberg, Ed., Robert E. Krieger Publishing Company, N.Y., 1979, pp 213-288.

50. J.Crank and G.S. Park, Diffusion in Polymers, Academic Press, N.Y., 1968, Chapters 1 and 8. 

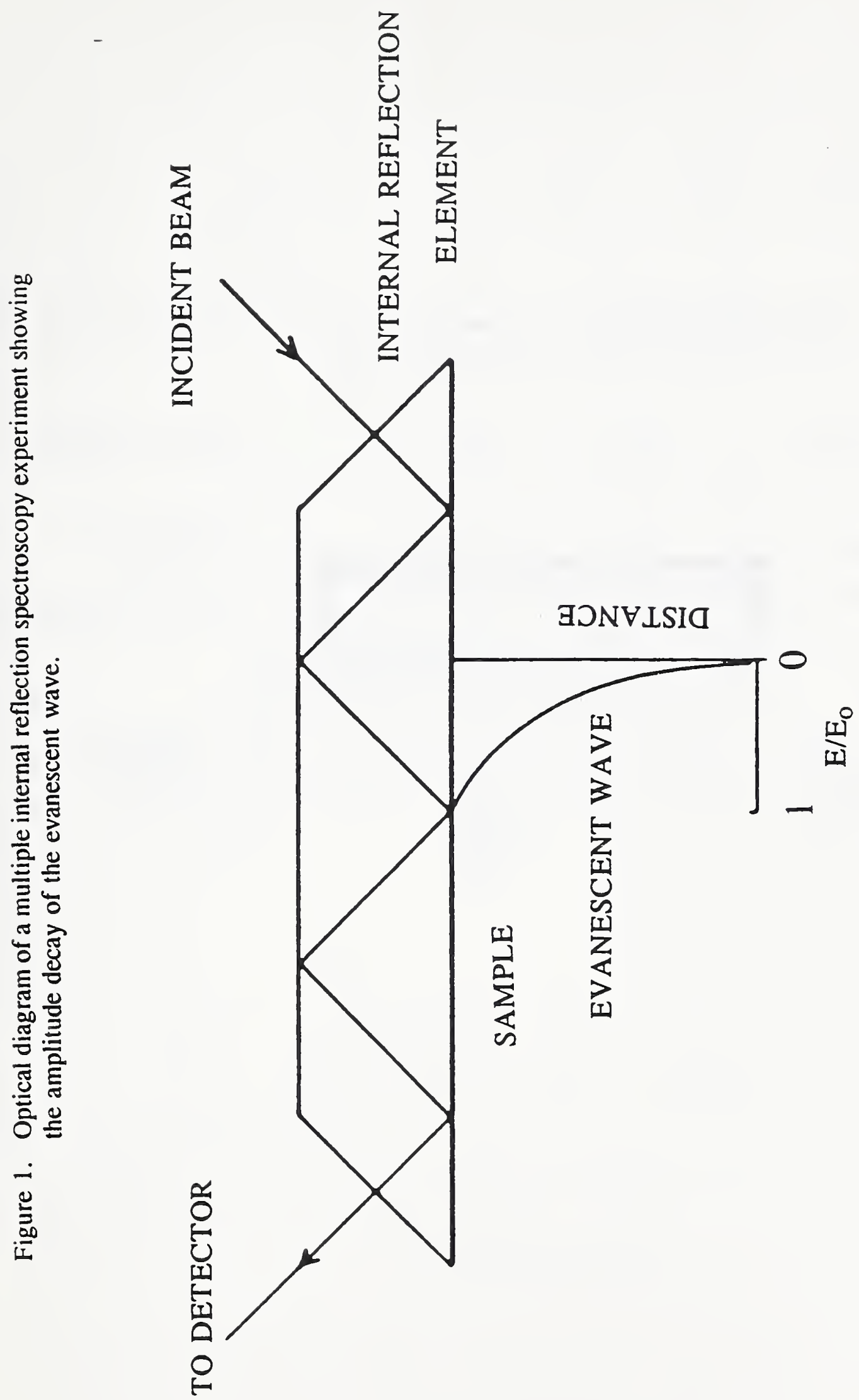
Figure 2. Specimen configuration and experimental setup for in situ measurement of water at the asphalt/model siliceous aggregate interface.

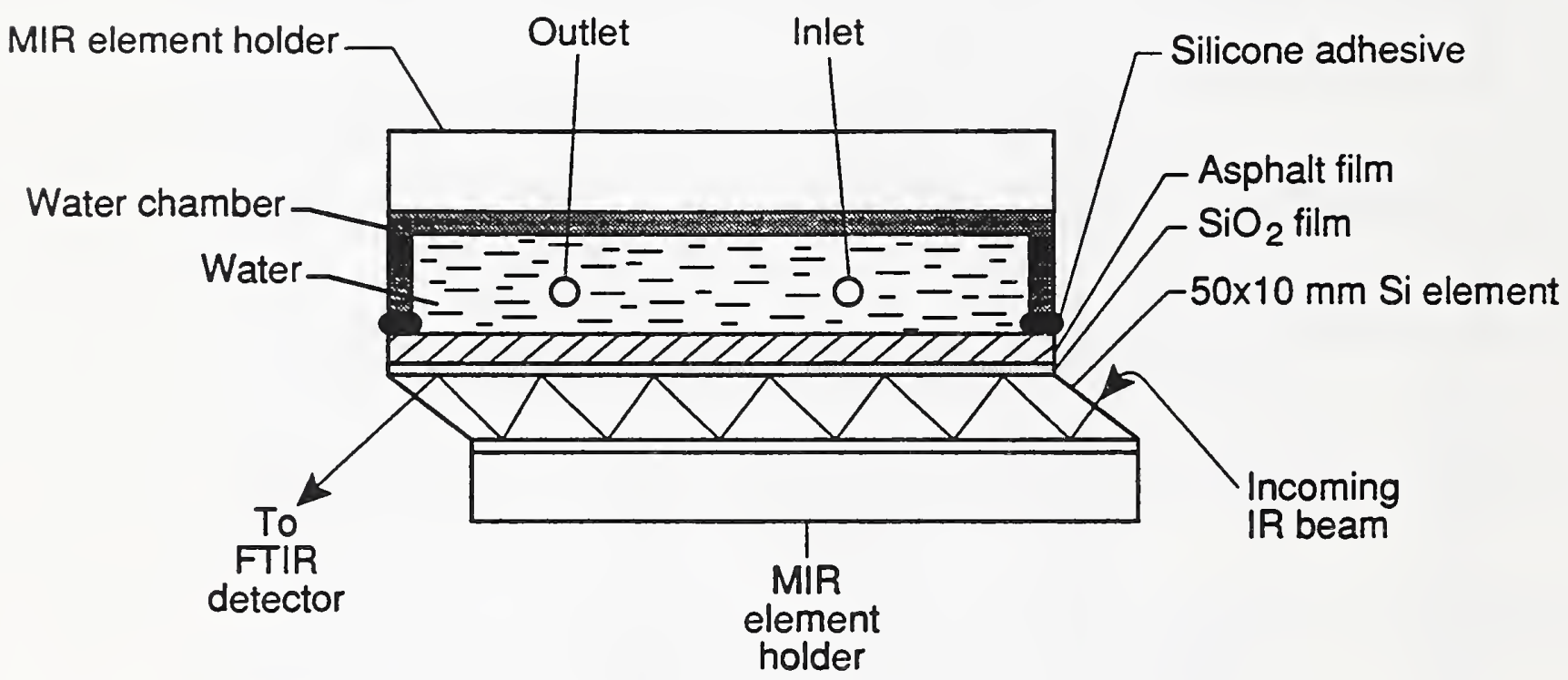




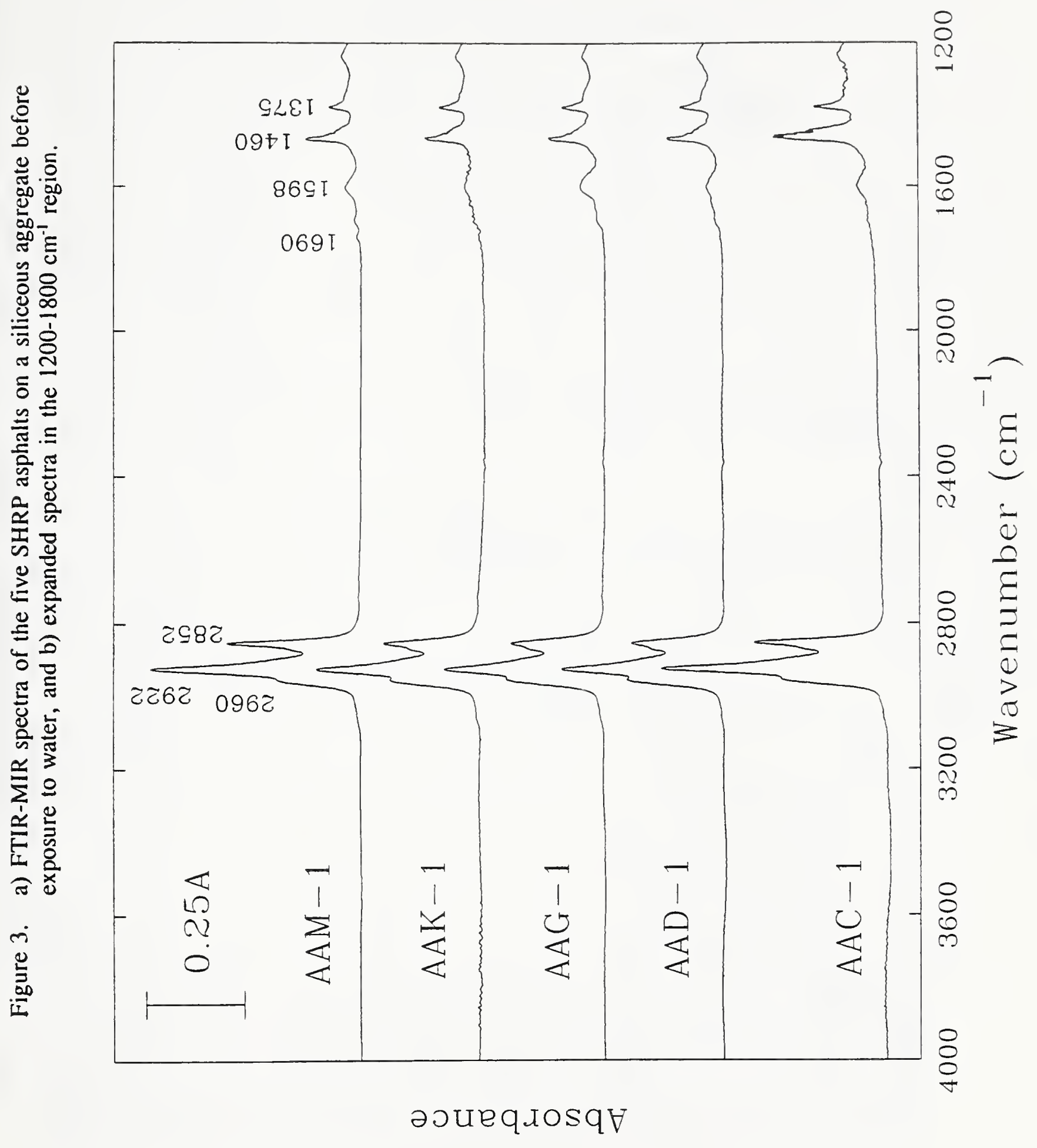




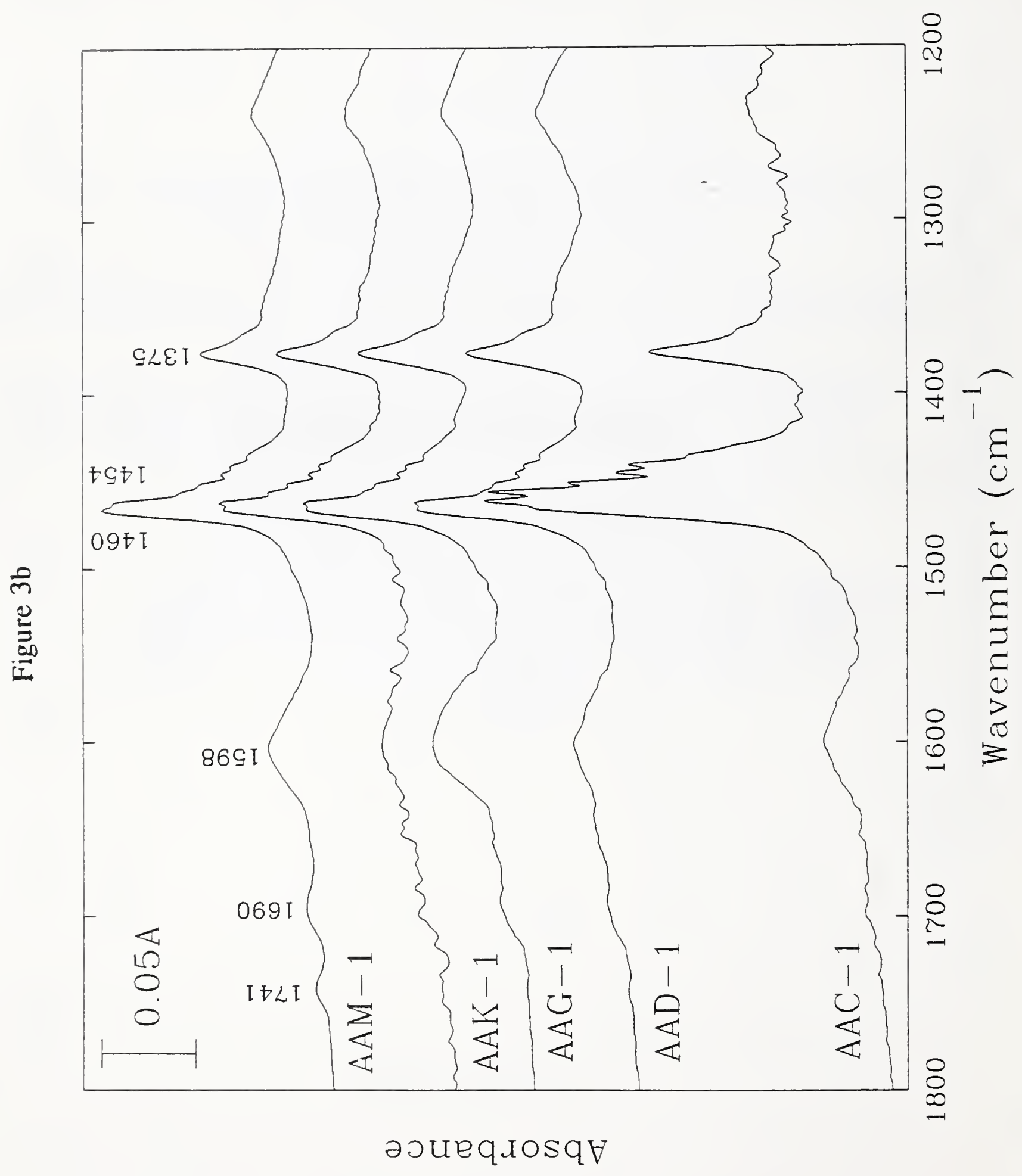




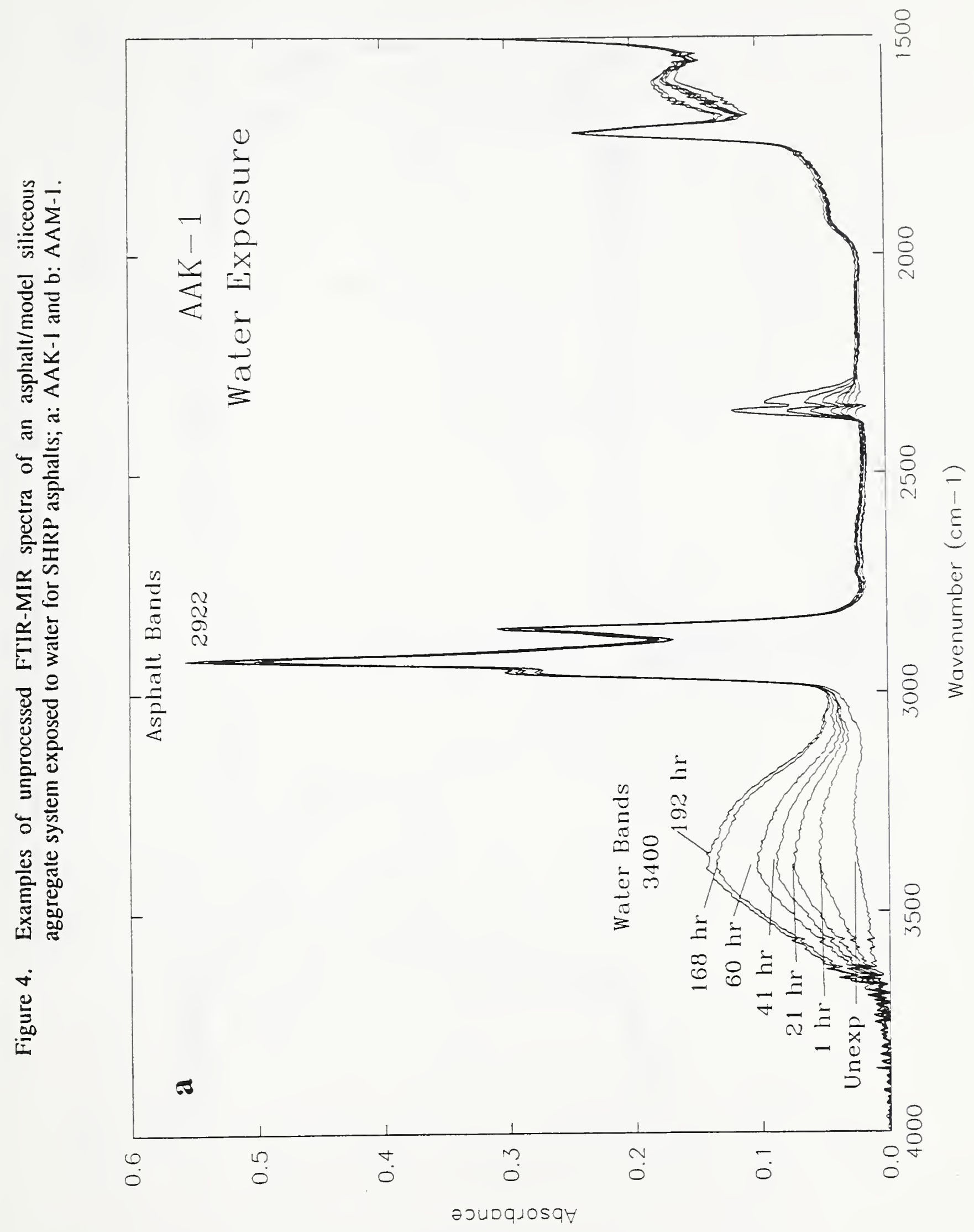




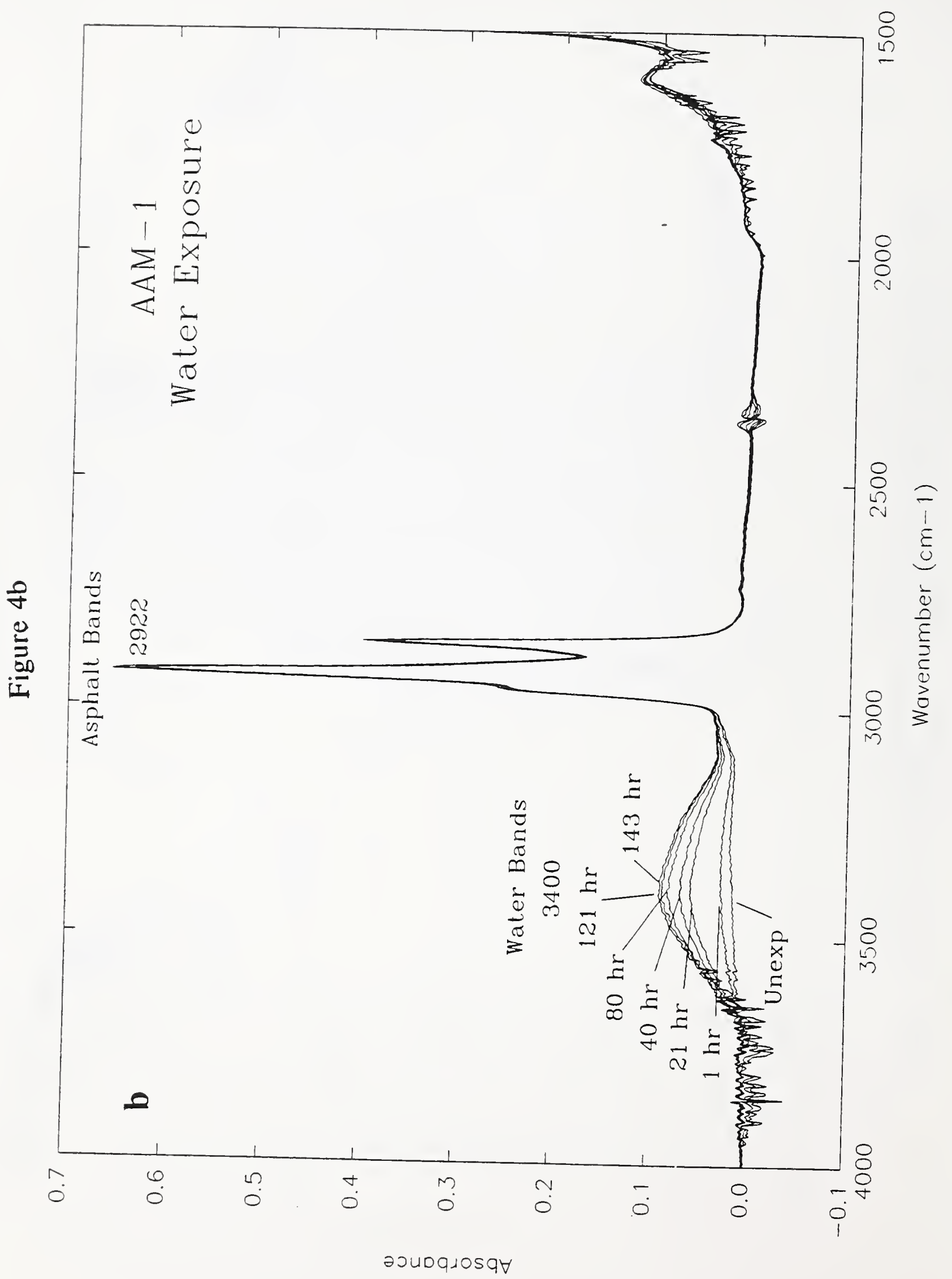




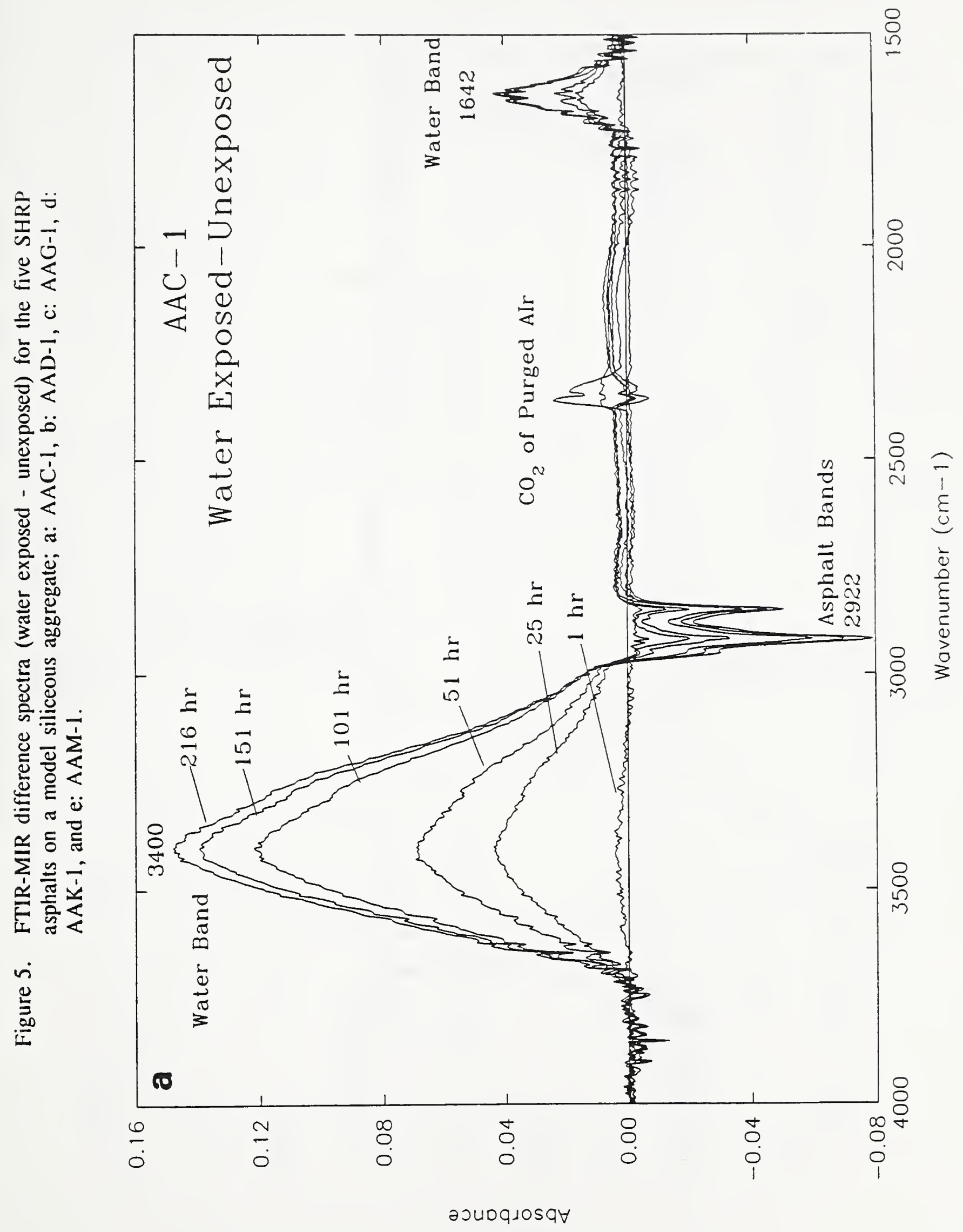




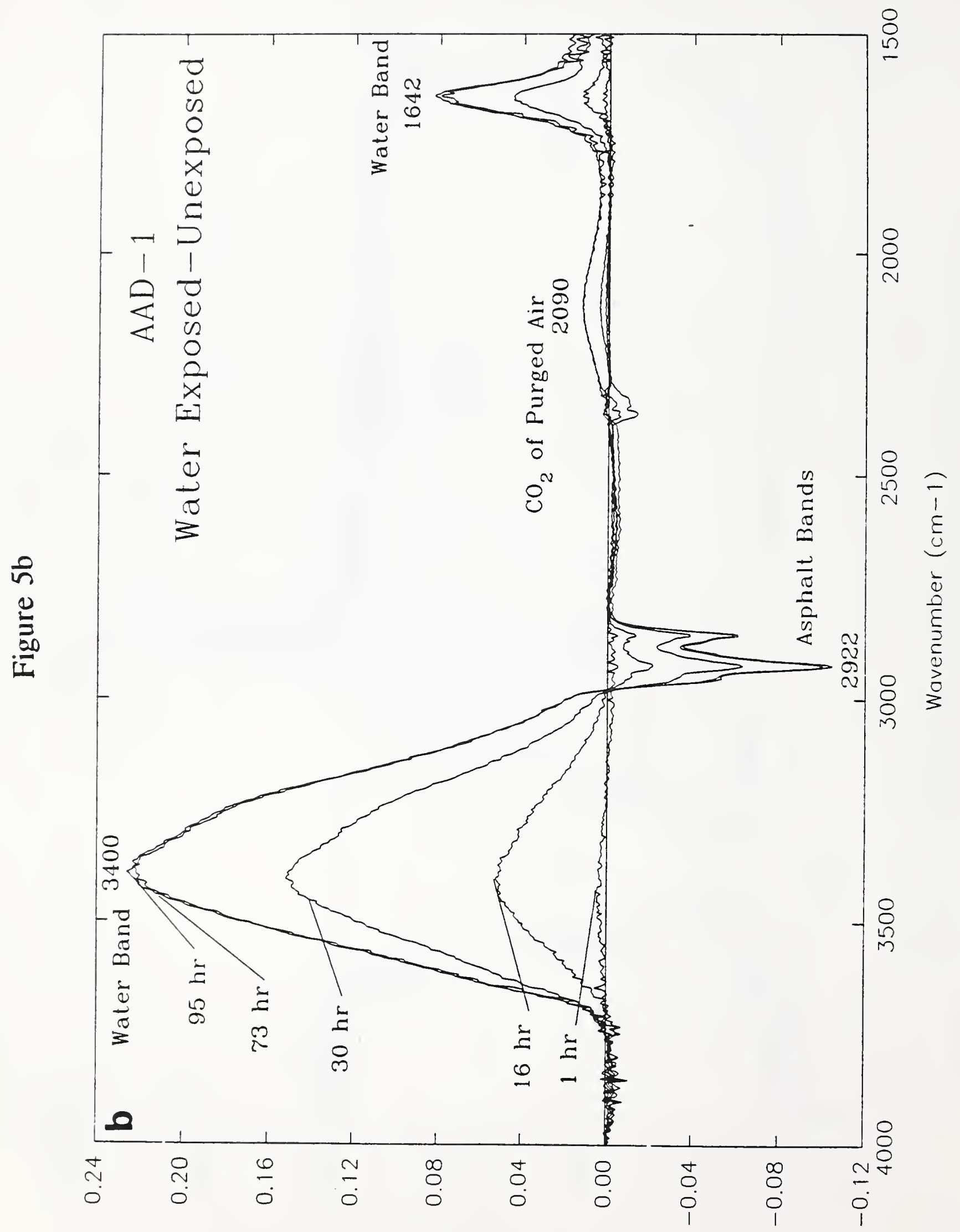

วงUDQ10Sq7 


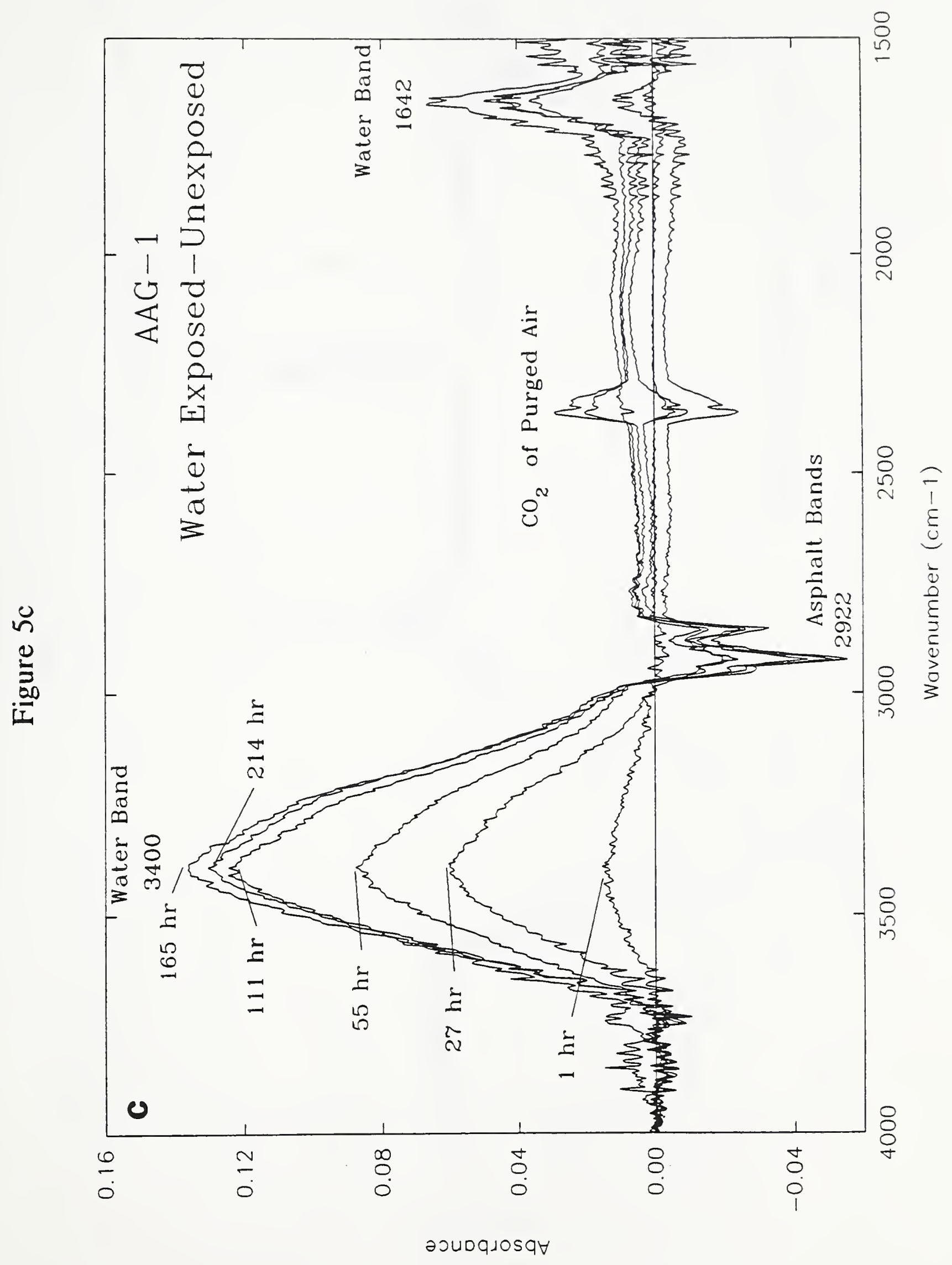




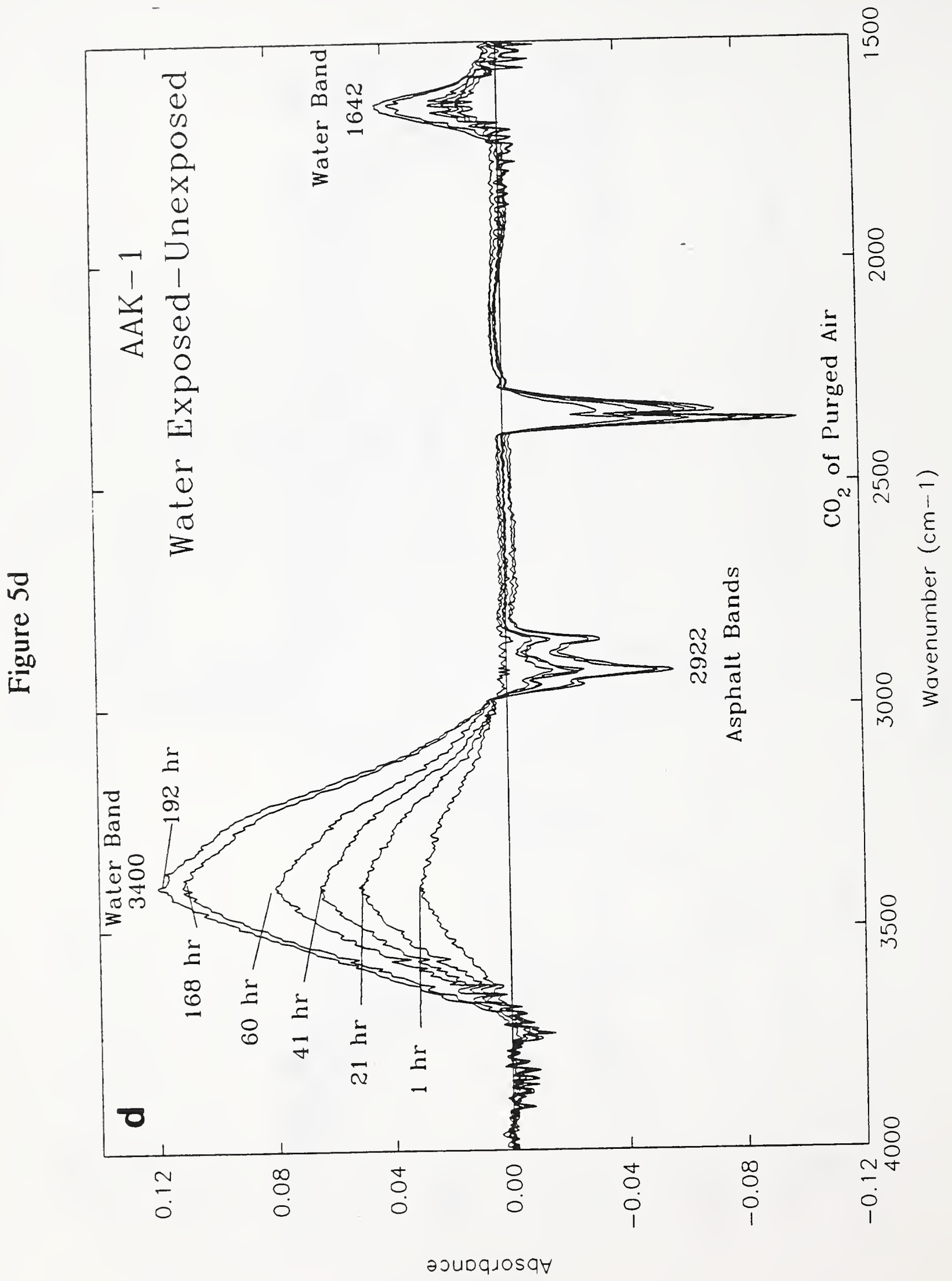




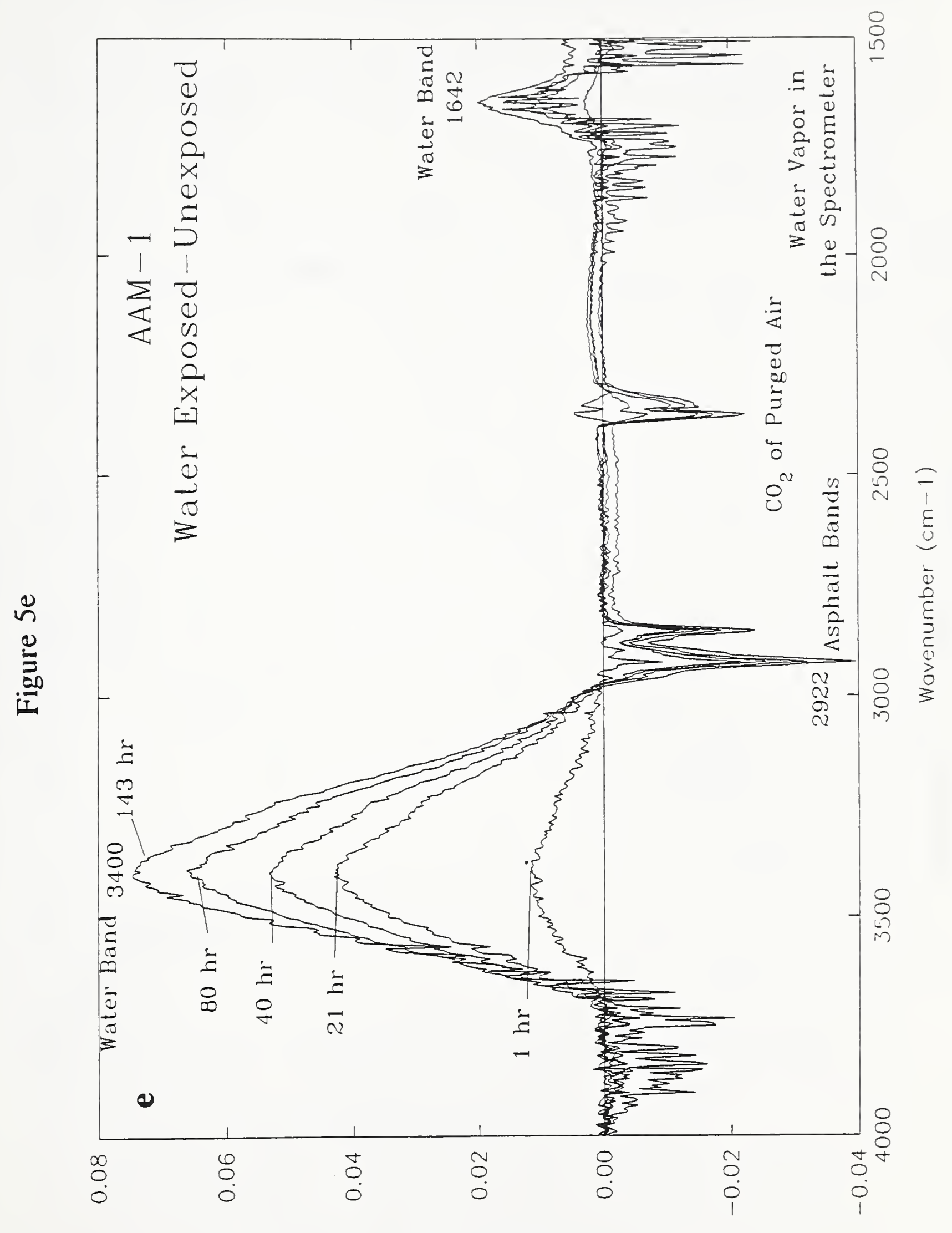

วगUDqJosq 


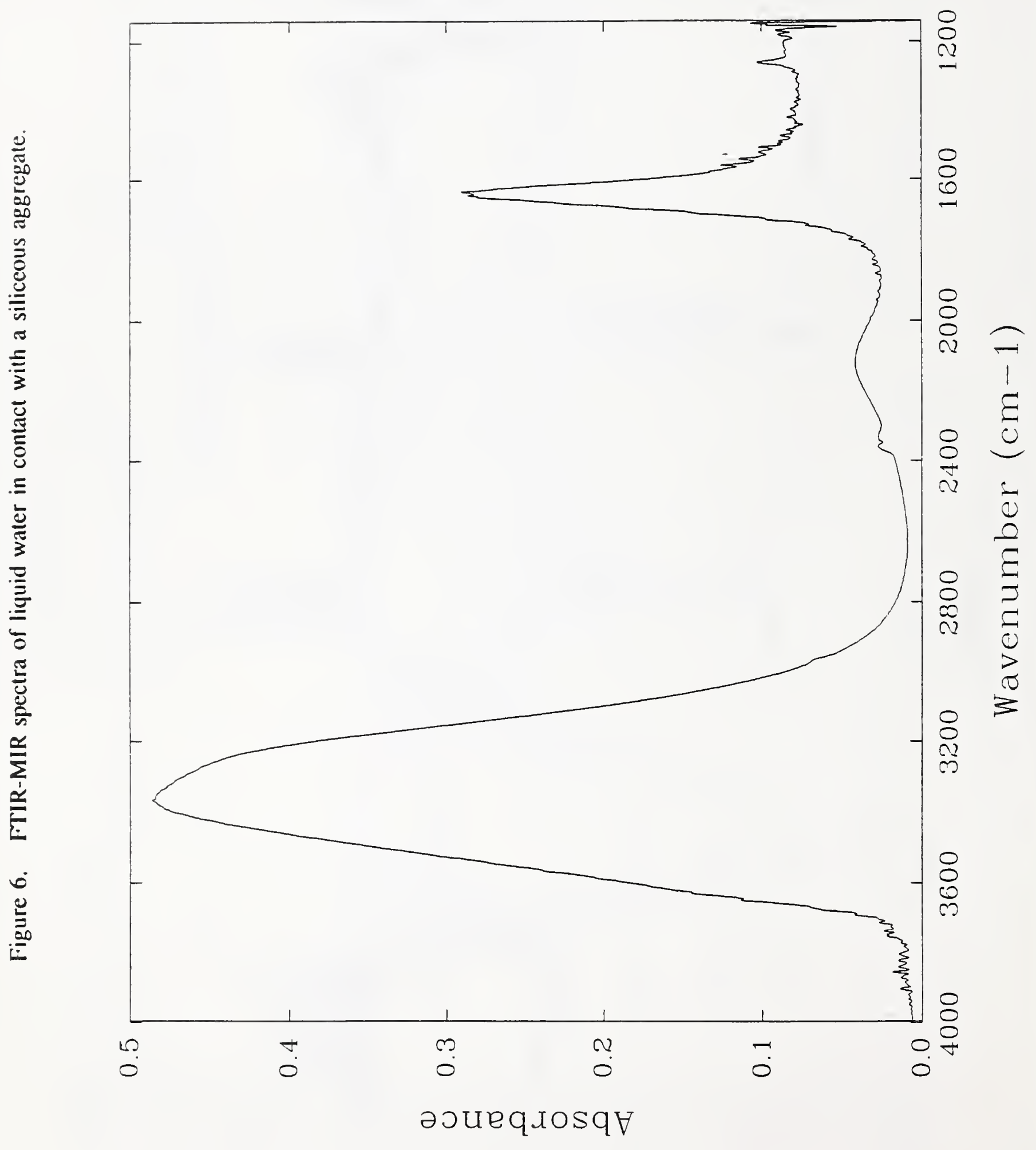


Figure 7. Intensity increase of water $\mathrm{OH}$ group as a function of exposure time for the five SHRP asphalts on a model siliceous aggregate. (Each dot represents one data point.)

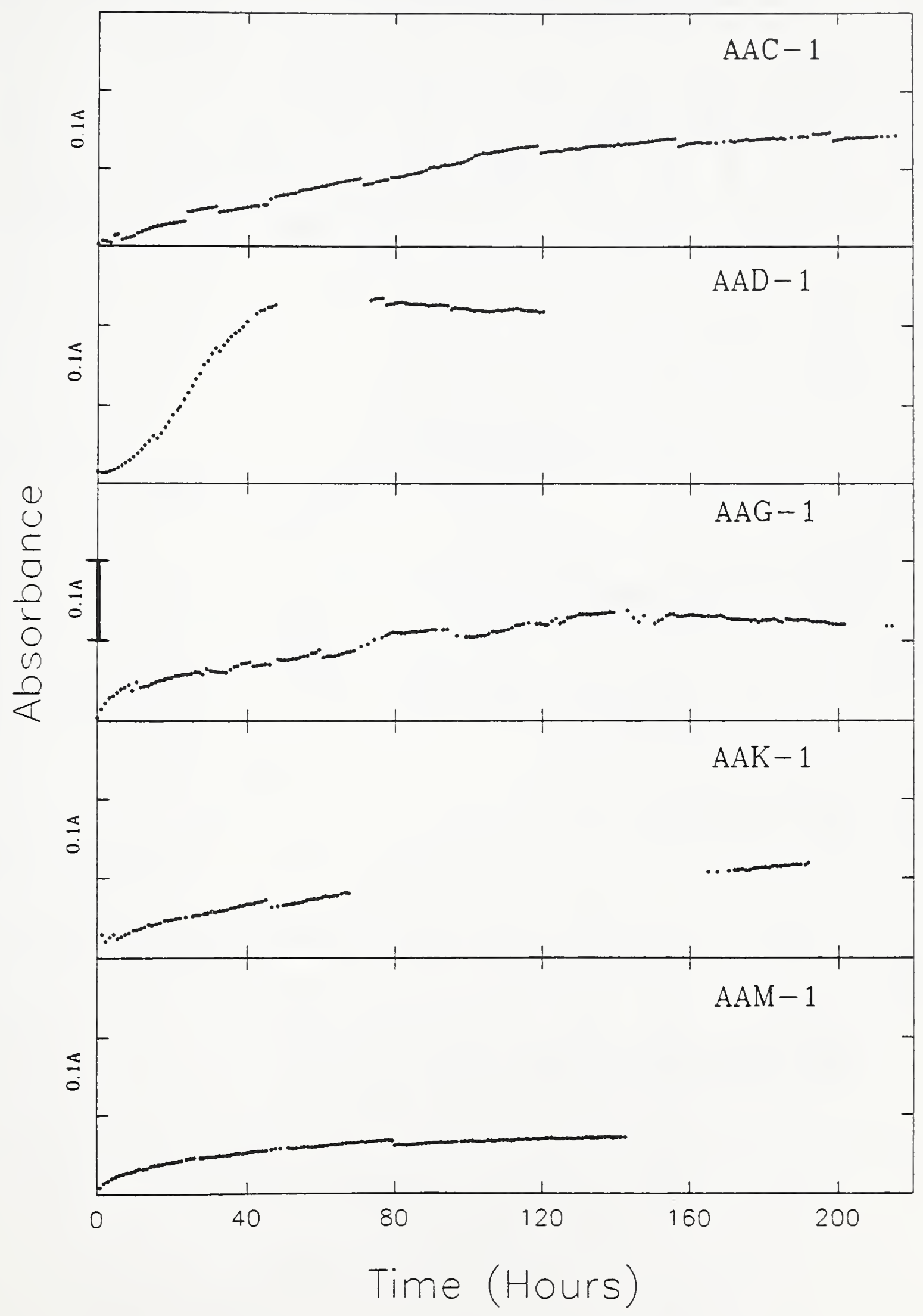


Figure 8. Intensity decrease of asphalt $\mathrm{CH}$ group as a function of exposure time for the five SHRP asphalts on a model siliceous aggregate. (Each dot represents one data point.)

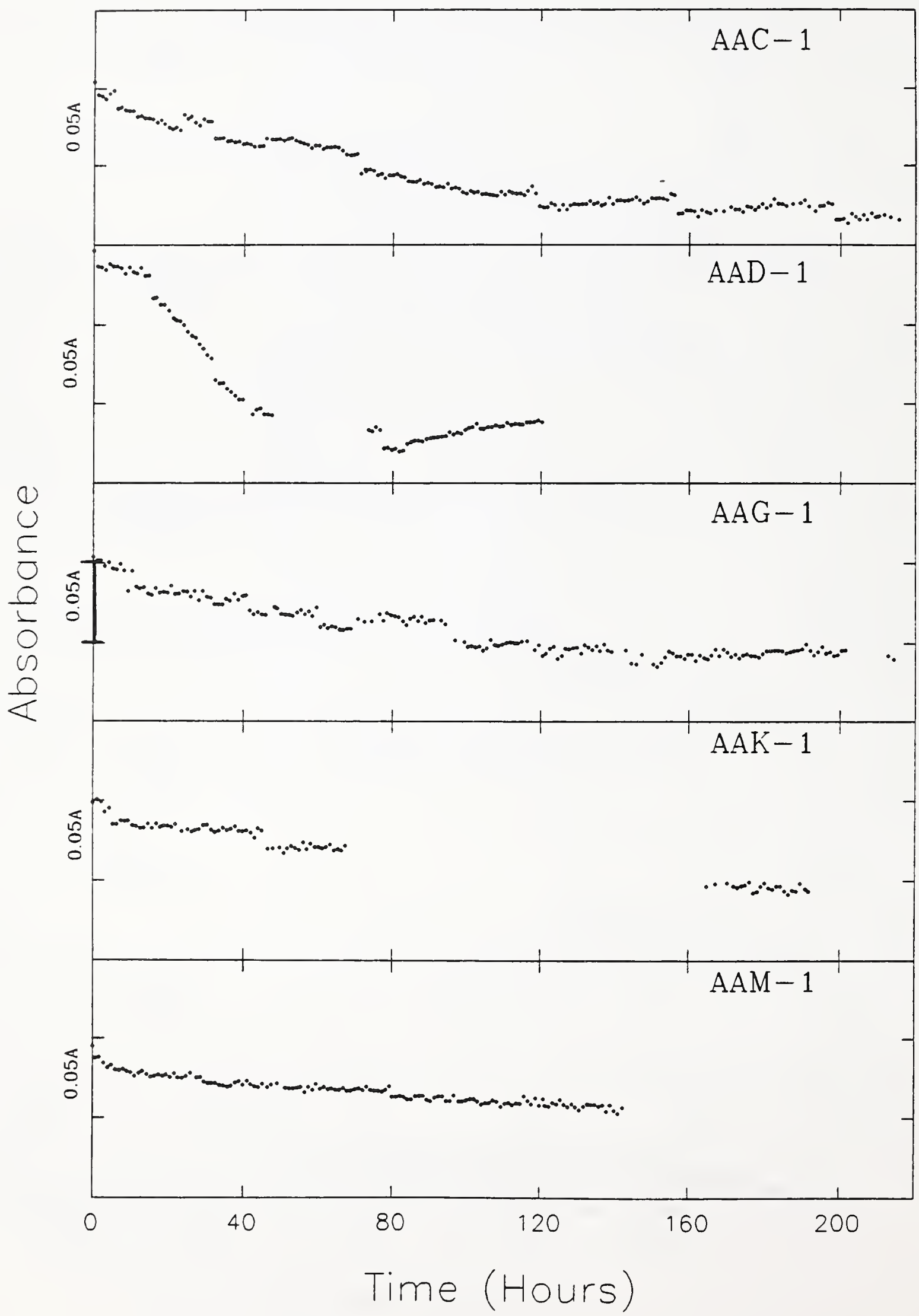




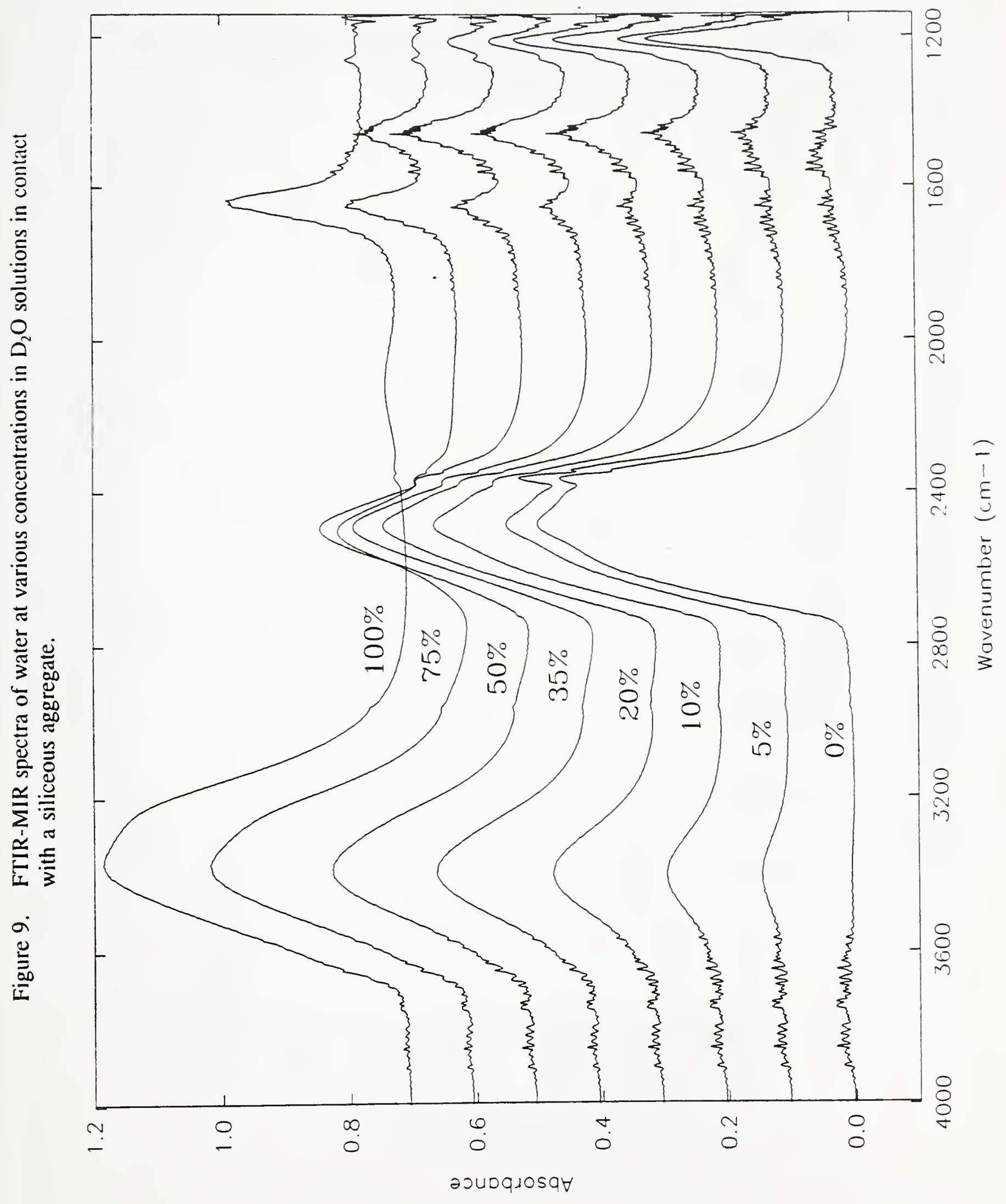




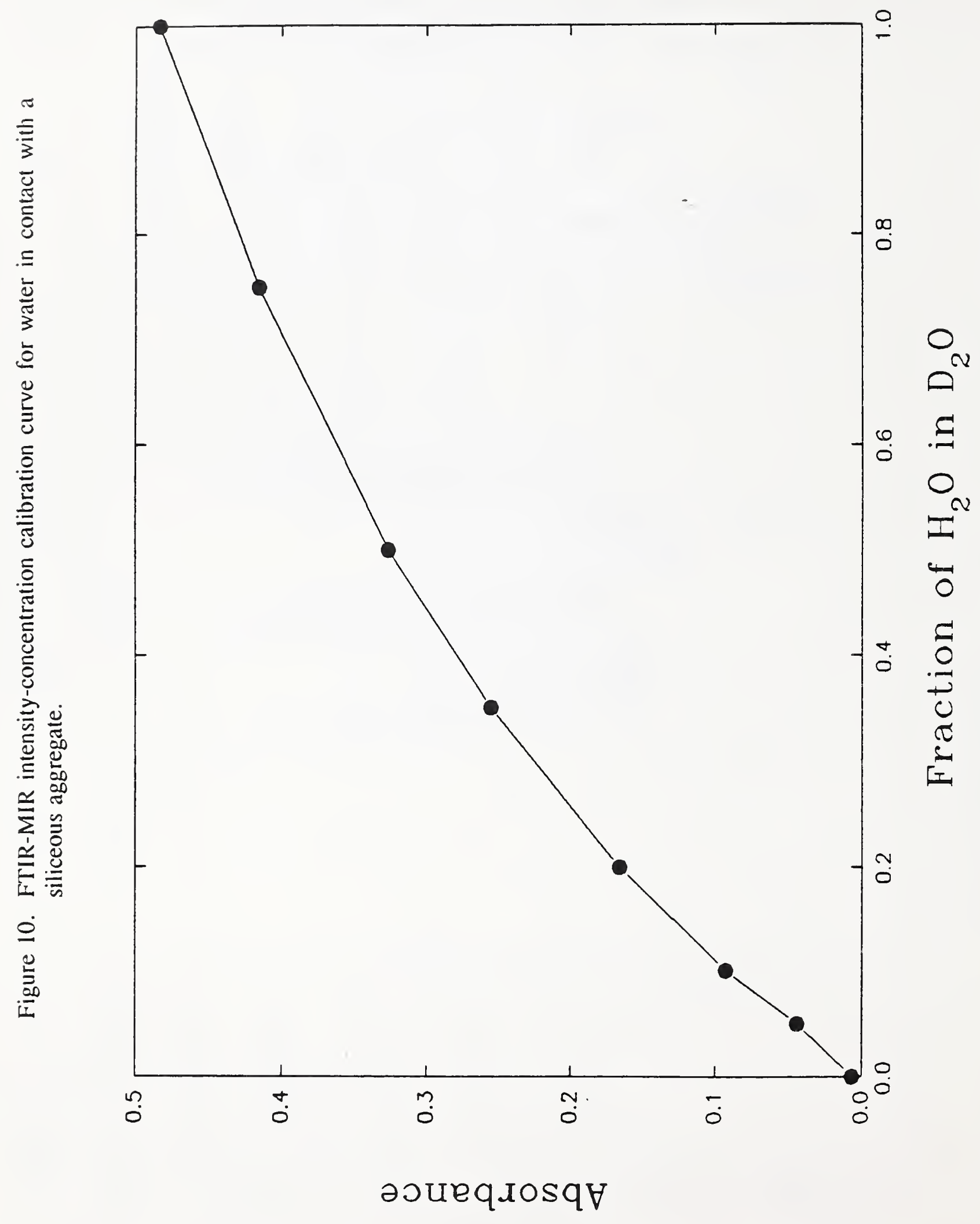



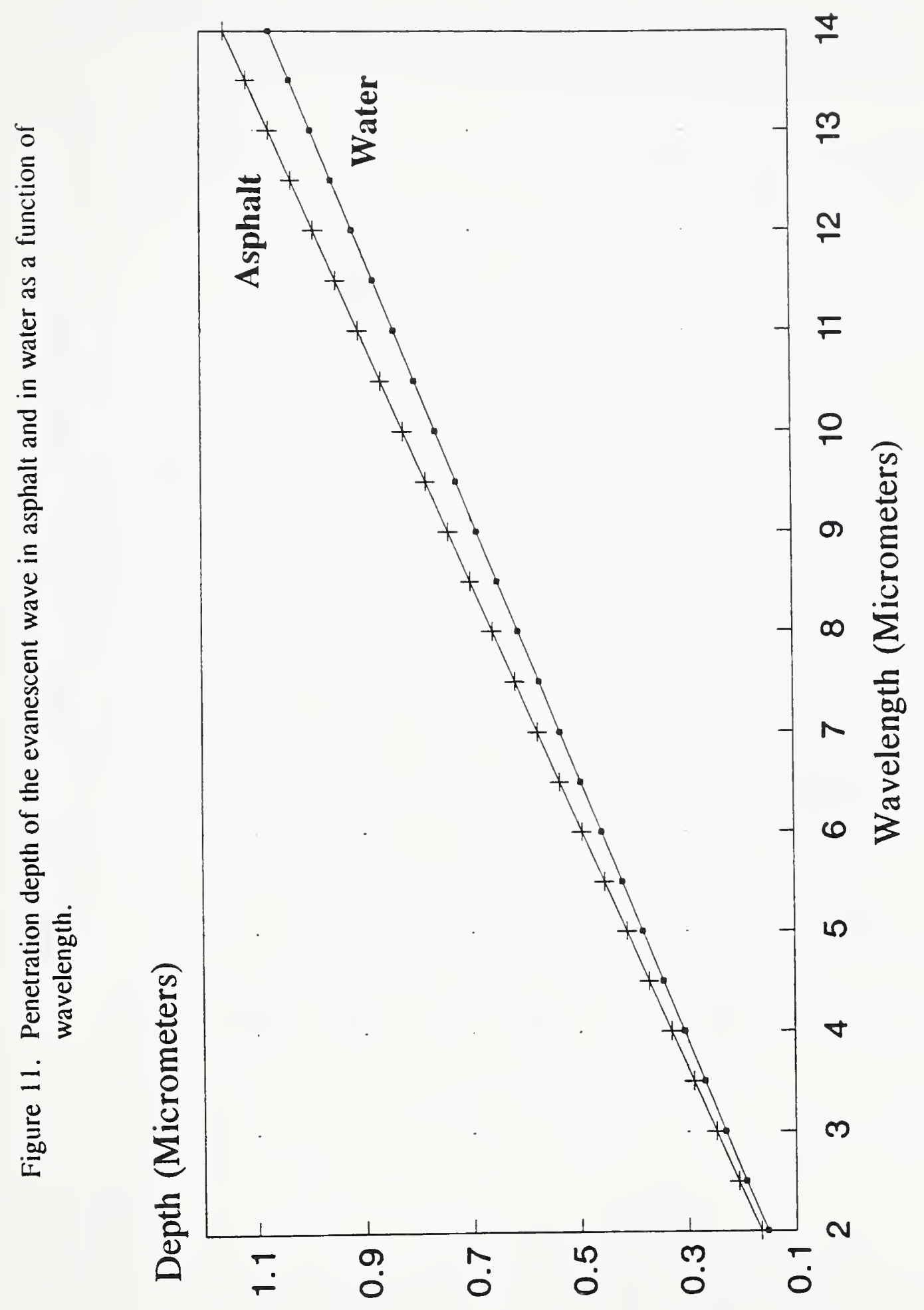
Figure 12. Water absorption in five SHRP asphalts as a function of time. (The vertical bar at each data point indicates the deviation from the means.)
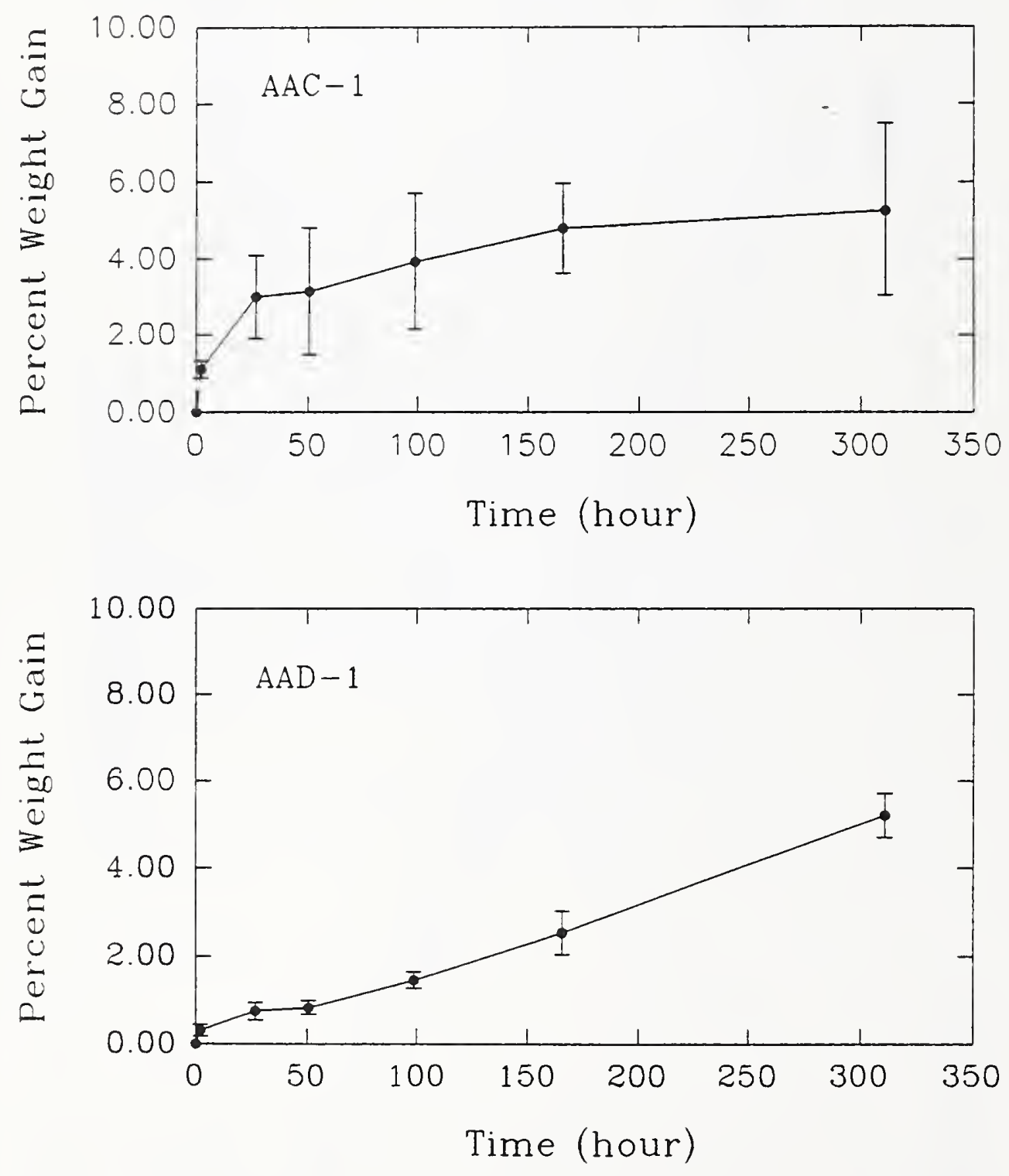
Figure 12, continued
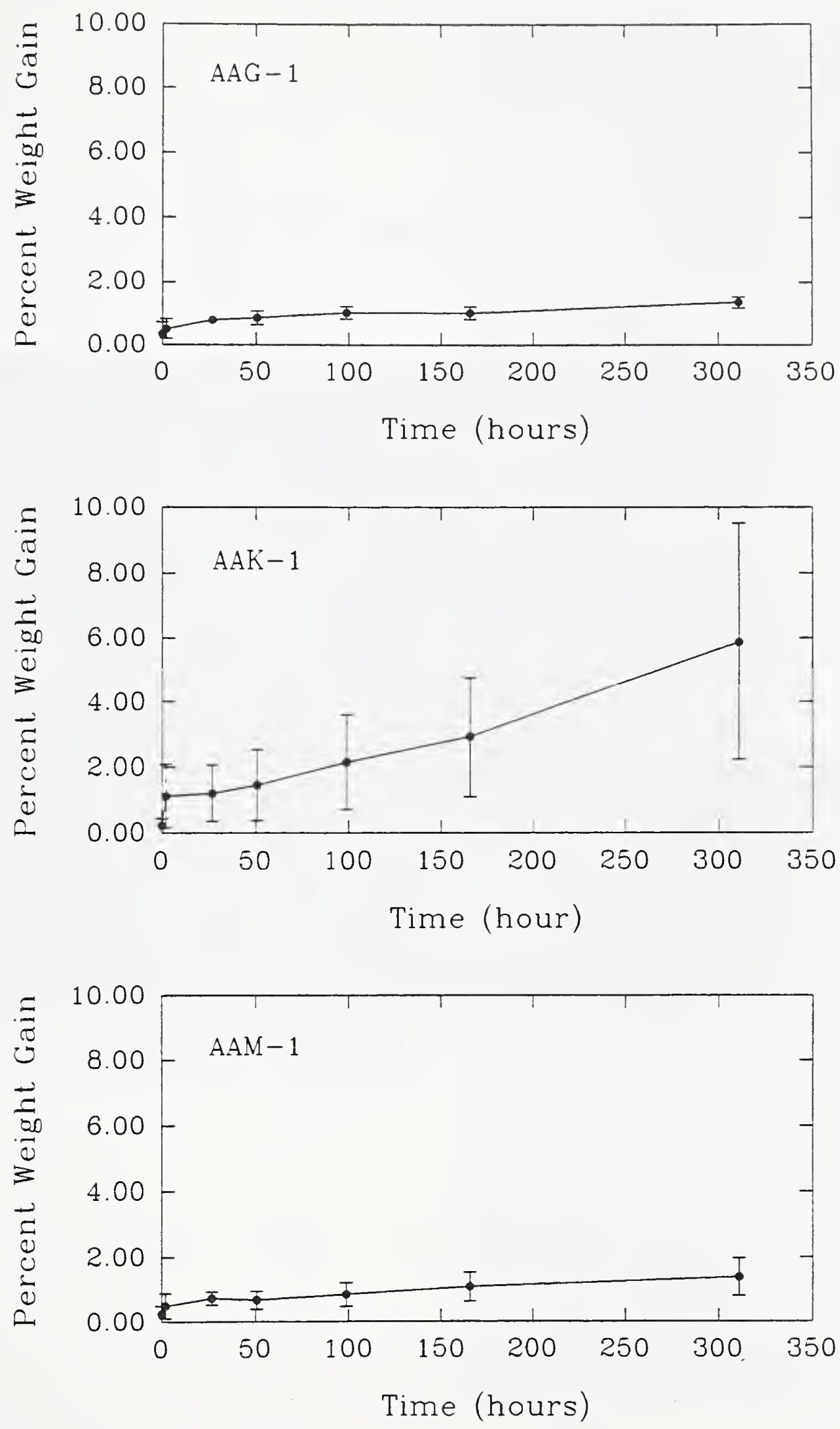
Figure 13. Surface appearances of five SHRP asphalts before and after exposure to water for 1075 hours.

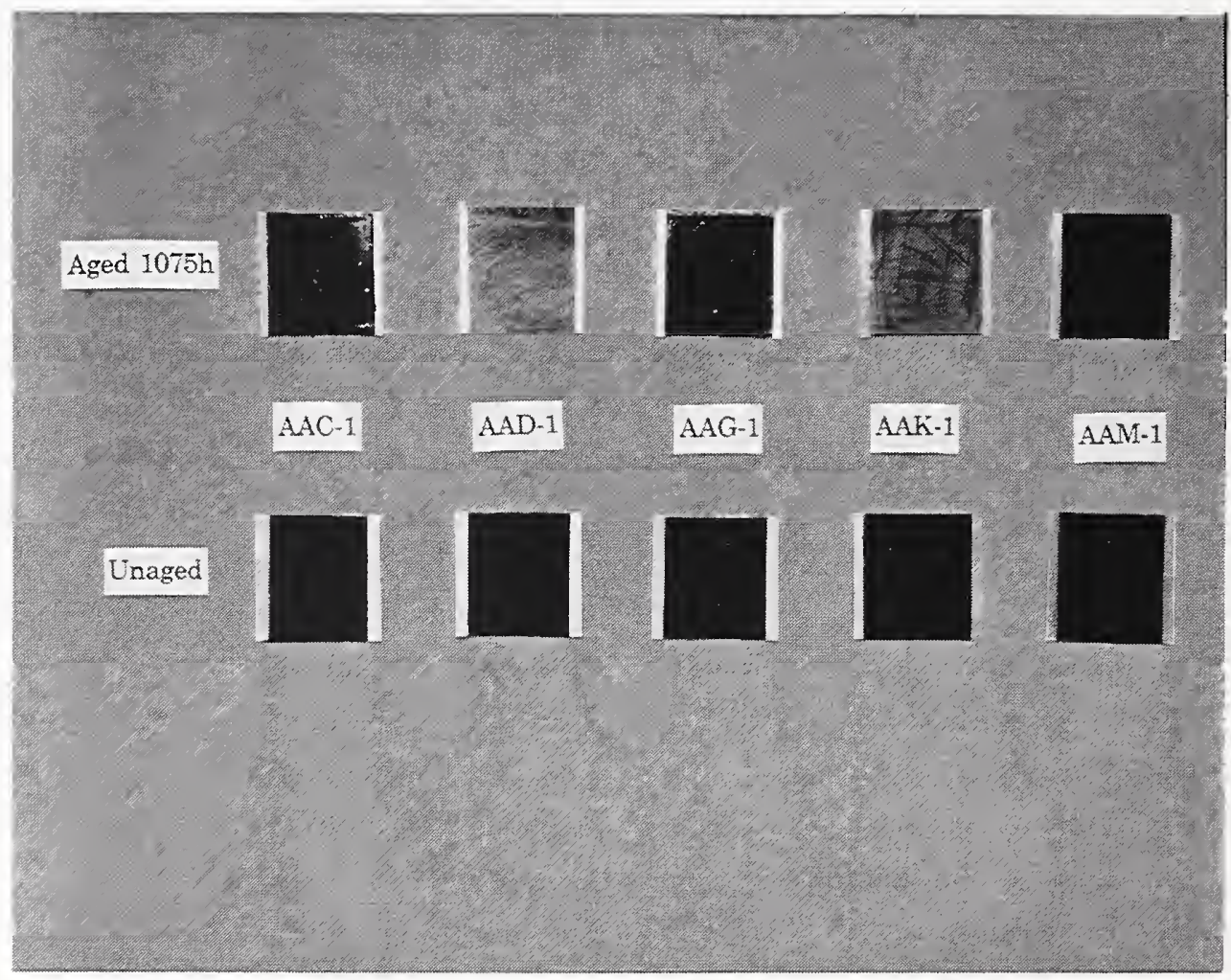



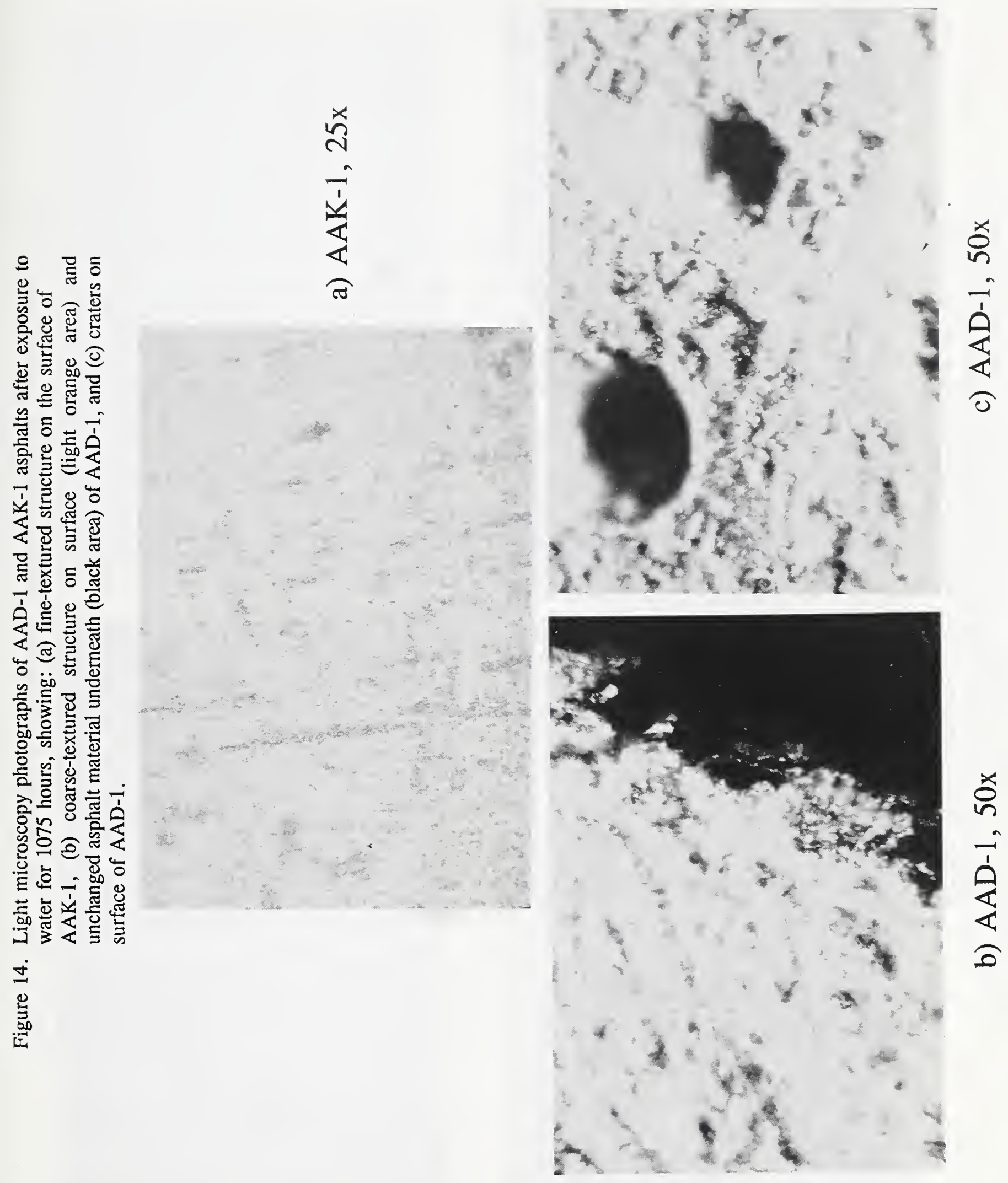


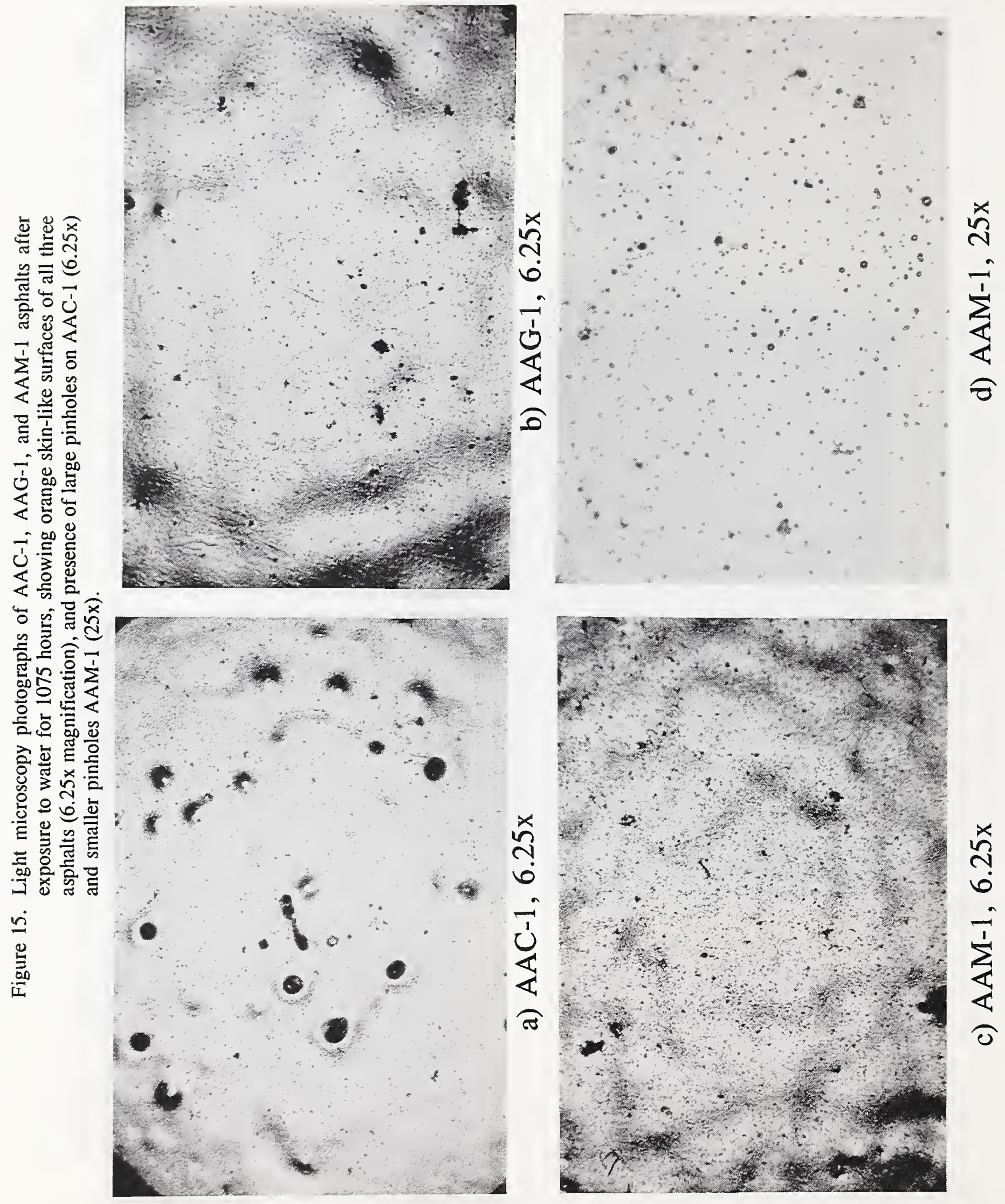




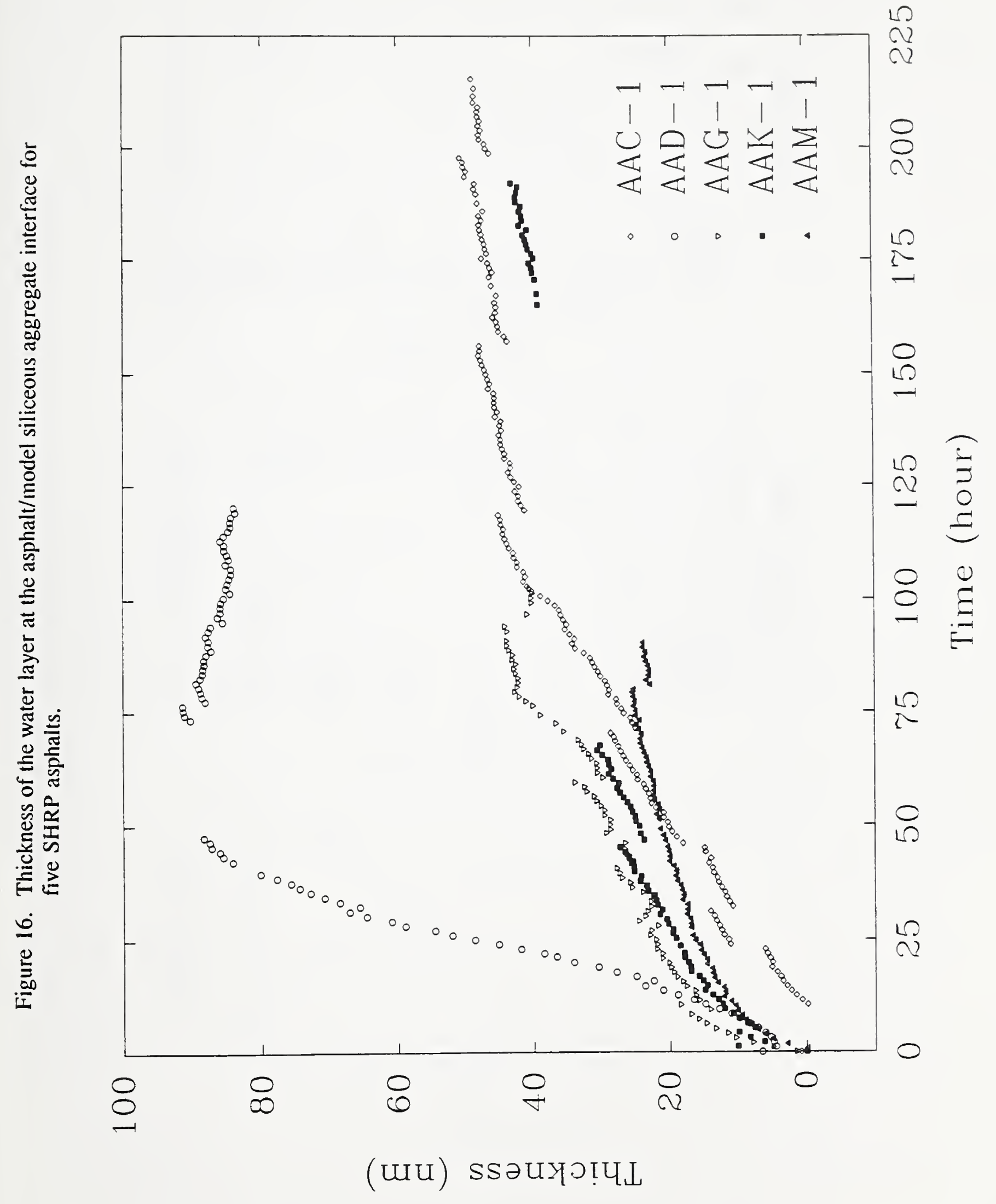


Figure 17. Total water detected near the asphalt/model siliceous aggregate interface (upper curves) and amount of the water layer at the asphalt/model siliceous aggregate interface (lower curves) for five SHRP asphalts.
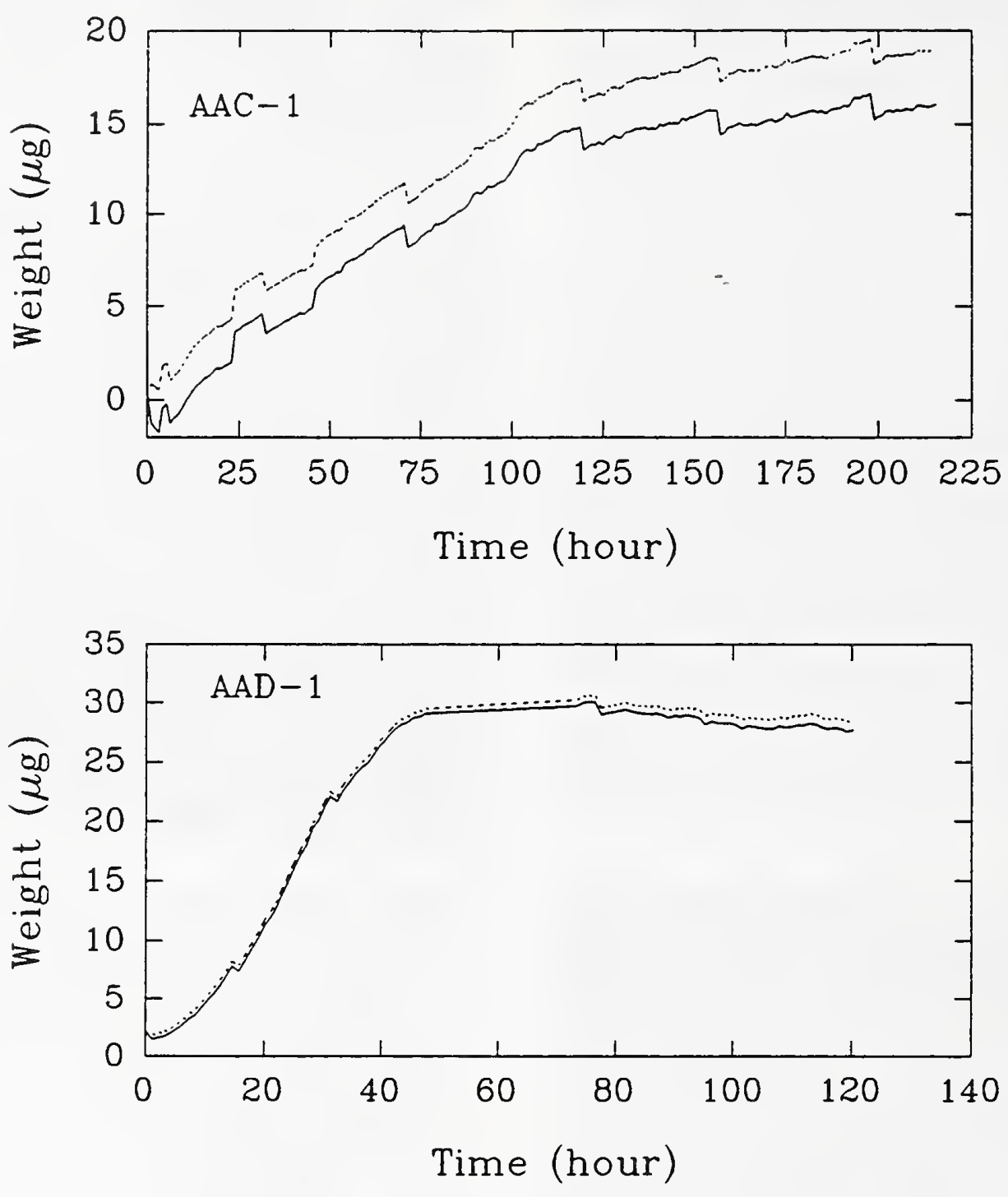
Figure 17, continued
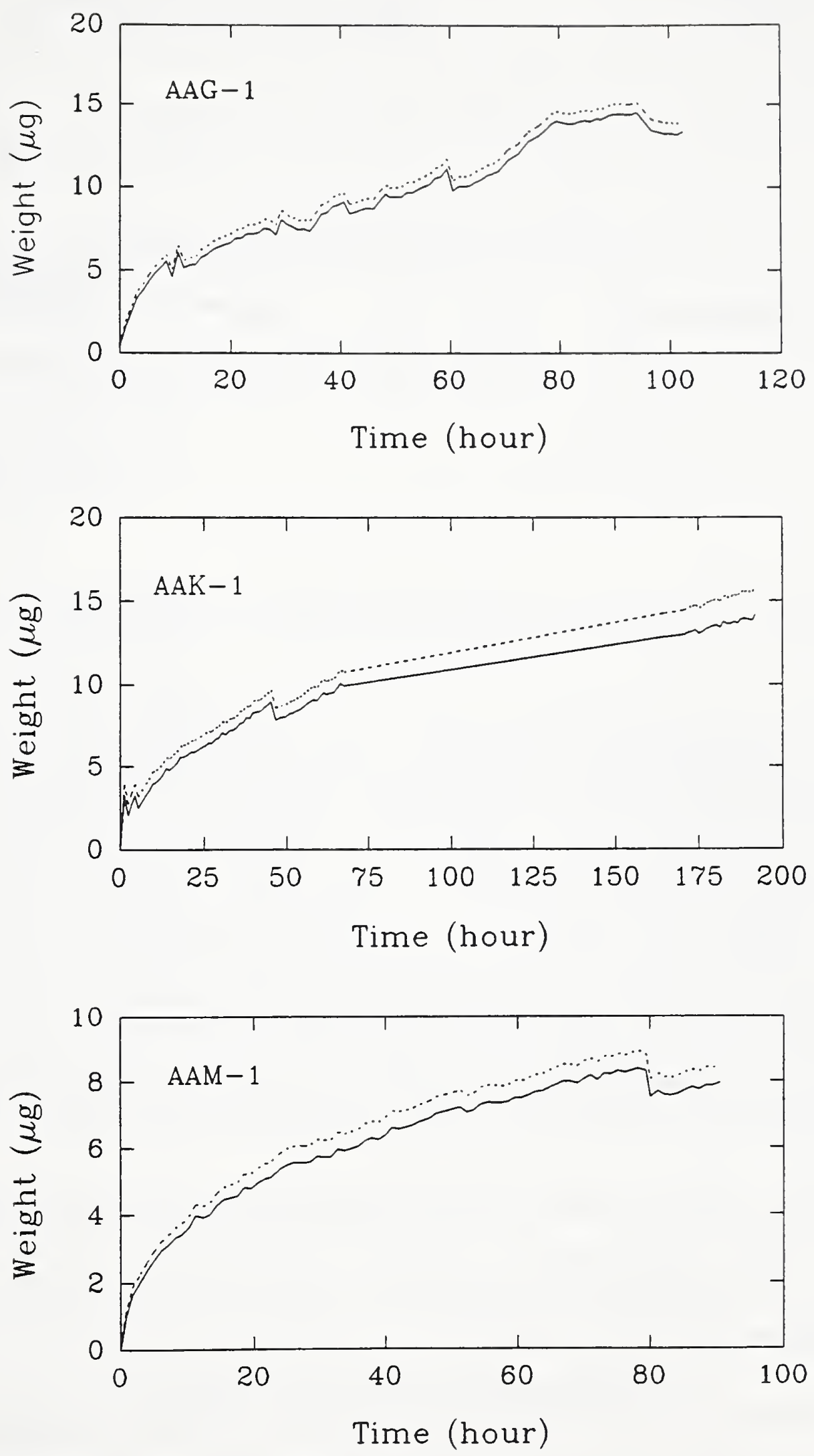


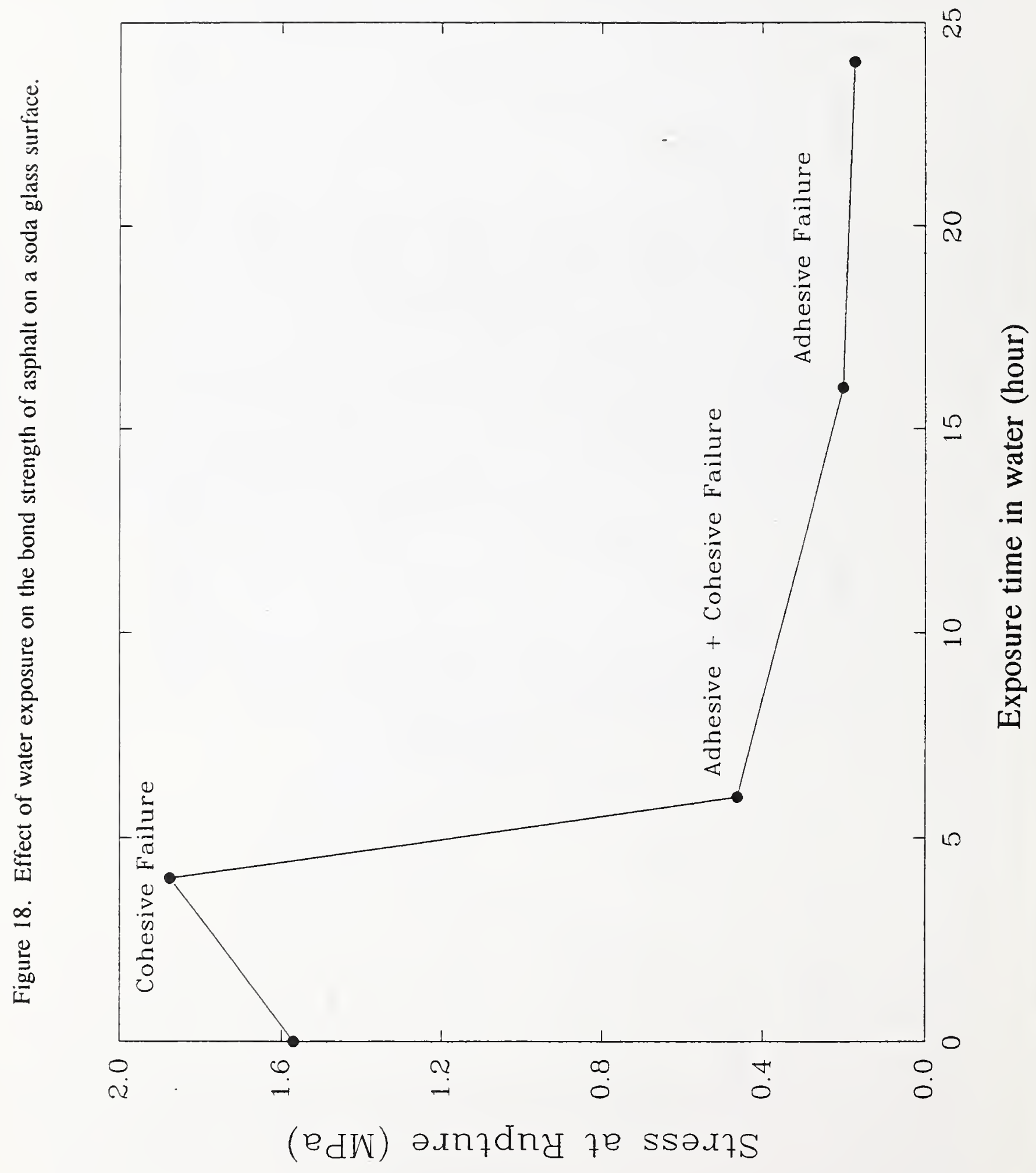




\section{BIBLIOGRAPHIC DATA SHEET}
2. PERFORMIMO ORQANIZATION REPORT NUMBER Division 862
3. PUBUCATION DATE

\section{TITLE AND SUBTITLE}

Development of a Technique for In Situ Measurement of Water at the Asphalt/Model

Siliceous Aggregate Interface

5. AUTHOR(S)

Tinh Nguyen, W. Eric Byrd, Dale P. Bentz, and James Seiler, Jr.

6. PERFORMIMG ORGANIZATION (IF JOINT OR OTMER THAN MIST, SEE INSTRUCTIONS)

U.S. DEPARTMEMT OF COMMERCE

MATIONAL INSTITUTE OF STANDARDS AND TECHNOLOQY

CATTHERSBURG, WD 2009

\begin{tabular}{|l|} 
7. \\
\hline 8. TYNTRACT/ORANT MUMBER OF REPORT AND PERIOD COVERED \\
\hline
\end{tabular}

9. SPONSORING ORCANIZATION MAME AND COMPLETE ADDRESS (STREET, CTTY, STATE, ZP)

Strategic Highway Research Program

National Research Council

818 Connecticut Ave., NW

Washington, DC 20006

10. SUPPLEMENTARY MOTES

11. ABSTRACT (A 200-WORD OR LESS FACTUAL SUMMARY OF MOST SIOMIFCANT IMFORLATION. IF DOCUMENT INCUUDES A SIONIFICANT BIBLUOORAPAY OA UTERATURE SURVEY, MENTION TT HERE)

A technique based on Fourier transform infrared (FTIR) spectroscopy in the multiple internal reflection (MIR) mode was developed for measuring water in situ at the interface between an asphalt and a model siliceous aggregate. The technique required the coating of an asphalt layer of known thickness on an internal reflection element (IRE), which served as an optical guide to obtain an infrared spectrum. A water chamber was attached to the asphalt-coated IRE, and FTIR-MIR spectra were taken automatically at specified times without disturbance of the specimens. In situ water measurements for five Strategic Highway Research Program (SHRP) core asphalts (AAC-1, AAD-1, AAG-1, AAK-1, and AAM-1) on a hydrated, SiQ-covered Si IRE, which served as the model siliceous aggregate, were carried out using the technique. An FTIR-MIR study of water at different concentrations and experiments on water absorption in SHRP asphalts were also done for the quantitative analysis. Calculations were made to demonstrate that the water detected was at or near the asphalt/siliceous aggregate interface. The results have shown that the technique can detect and quantify water in situ at the asphalt/siliceous interface, and provide unique information on the transport properties of water through an asphalt layer attached to a substrate. The technique developed here should be useful for evaluating asphalt/siliceous model aggregate mixtures in terms of 1) water susceptibility of an asphalt/aggregate mixture, 2) effectiveness of antistripping agents, 3) effects of aggregate surface contamination and environmental temperature on water stripping, and 4) water diffusion through asphalts on an aggregate. The technique should also be effective in obtaining quantitative information on the transport of water and other compounds, both organic and inorganic, through a layer of any thickness of asphalt/aggregate mixture, cement, and concrete attached to a substrate. Results of an exploratory test method for measuring the bond strength of an asphalt on an aggregate in the presence of water are given.

\section{KEYWORDS (6 TO 12 ENTRIES; ALPLAETCAL ORDER; CAPTTALEE ONLY PROPER MAMES; AND SEPARATE KEY WORDS BY SEMICOLOMS)}

Aggregate; asphalt; aspahlt/aggregate interface; ATR spectroscopy; bonding strength;

diffusion; FTIR; in situ measurement; multiple internal reflection spectroscopy;

SHRP; quantitative; siliceous aggregate; stripping; water adsorption; water susceptibility 


